\title{
The Military Capabilities and Implications of China's Indigenous Satellite-Based Navigation System
}

\section{Geoffrey Forden}

China has orbited a three-satellite constellation for space-based navigation known as Beidou. This article uses the constellation geometry, as determined by the NORAD space-surveillance system and publicly available from NASA, to estimate the accuracy available to a user of the Beidou system. Limited in terrestrial coverage to roughly the Asian subcontinent, this system requires a user either to go through an iterative procedure ill-suited to most military applications or to provide his or her own standard of time by carrying a high-precision clock. The iterative method does provide accuracies comparable to NAVSTAR/GPS over a restricted area of the Earth. Carrying an atomic clock, however, allows the system to be used in a mode that can provide sufficient accuracy to be used on MIRVed Chinese ICBMs en route to the United States and make a significant improvement in accuracy. Surprisingly, those modes of operation do not provide sufficient accuracy for most conventional military users.

\section{INTRODUCTION}

The world has become familiar with satellite-based navigation systems that have global reach and can be accessed by inexpensive user-terminals. These systems, epitomized by the U.S. NAVSTAR $\backslash$ GPS, have over 20 satellites in medium Earth orbits and inclinations near 54 degrees. ${ }^{1}$ It therefore comes as somewhat of a surprise that China would orbit a seemingly regional

Received 14 January 2004; accepted 30 April 2004.

Address correspondence to Geoffrey Forden, Massachusetts Institute of Technology, Building E28-620, 292 Main St., Cambridge, MA 02139. E-mail: forden@MIT.EDU

Geoffrey Forden, Massachusetts Institute of Technology, Cambridge, MA. 
system-the Beidou navigation system-based on two or perhaps three geostationary satellites. (China's declared concept of operations, discussed below, is based on two satellites while the website for China's space agency ${ }^{2}$ says that the third satellite, launched on 24 May 2003, completed the constellation.)

China has declared ${ }^{3}$ its space-based system will be used for civilian purposes such as supporting "road traffic, rail transport, [and] offshore operation[s]." The analysis presented here shows that the presently orbited system, operated in the mode declared by China, can provide such users with latitude and longitude estimates comparable to NAVSTAR $\backslash$ GPS but only if the user's position is calculated through a fairly complex iterative procedure that assumes a known altitude. However, the user must send a radio signal back to the satellite and have the central control center calculate his new position. Such radio transmissions could reveal the user's position and seems ill-suited to most military applications. ${ }^{4}$

The accuracy of a navigation system has direct implications for the system's applications and can allow the analyst to independently evaluate how the system might be used. This article analyzes the accuracies a user might expect using the Beidou system in various modes, concentrating in particular, on military applications.

In the following sections, the Beidou launch and orbital station-keeping history is reviewed followed by a discussion of China's declared concept of operations. The section following that introduces the mathematics needed to calculate the accuracy of systems using fewer than four satellites. (A more complete treatment of the needed mathematics is given in an Appendix at the end of this article.) With that foundation laid, the accuracies that could be expected using China's concept of operations are analyzed in the following section. Sections after that analyze the accuracies associated with alternative modes of operation for the system.

While these modes of operation are different from the declared mode of operation, they could be still be used with the current space-based hardware. Furthermore, these modes of operation might be more appropriate for many military applications since the user remains a passive user of the system and does not have to send a signal back to the satellite, potentially revealing his location. The results show, however, that these modes of operation could not achieve accuracies comparable to NAVSTAR $\backslash$ GPS for conventional military uses. Surprisingly, the Beidou system could contribute to significantly improving China's ICBM accuracies, especially if China modernizes its ICBM force with MIRVed warheads as some analysts have suggested. 
Table 1: Parameters of the Beidou constellation.

\begin{tabular}{lllllll}
$\begin{array}{l}\text { Satellite } \\
\text { name }\end{array}$ & $\begin{array}{l}\text { NORAD } \\
\text { catalog } \\
\text { number }\end{array}$ & $\begin{array}{l}\text { Launch } \\
\text { date }\end{array}$ & $\begin{array}{l}\text { Longitude } \\
\text { (degrees) }\end{array}$ & $\begin{array}{l}\text { Inclination } \\
\text { (degrees) }\end{array}$ & $\begin{array}{l}\text { Apogee } \\
\text { (km) }\end{array}$ & $\begin{array}{l}\text { Perigee } \\
\text { (km) }\end{array}$ \\
\hline Beidou 1A & 26599 & $\begin{array}{c}30 \text { October } \\
2000\end{array}$ & 139.9 & 0.05 & 35804 & 35770 \\
Beidou 1B & 26643 & $\begin{array}{c}20 \text { December } \\
2000\end{array}$ & 80.2 & 0.07 & 35801 & 35773 \\
Beidou 1C & 27813 & $\begin{array}{c}24 \mathrm{May} \\
2003\end{array}$ & 110.4 & 0.15 & 35829 & 35747 \\
\hline
\end{tabular}

\section{THE BEIDOU CONSTELLATION}

The launch history and current ${ }^{5}$ operational parameters of the three Beidou satellites are given in Table 1. The first two satellites were orbited in late 2000, the first in October and the second in December of that year. Then China waited approximately $2 \frac{1}{2}$ years before orbiting the third satellite. During this period, China performed station-keeping operations on each of those satellites. Figure 1 shows the history of the longitude of these three satellites and the areas on the Earth's surface where they are visible. The intersection of all three ovals is the

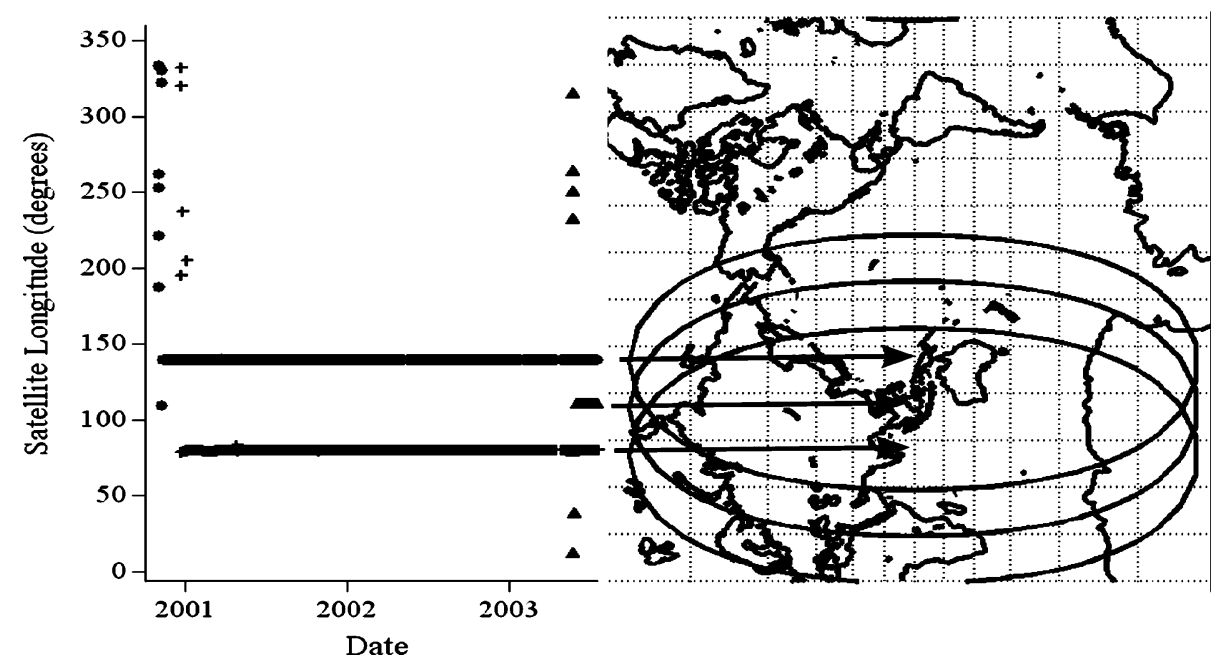

Figure 1: Longitudinal history of the Beidou constellations. The arrows point to the approximate position of the satellites on the equator. Ovals on the Mercator projection show the areas where each satellite is visible. The intersection of all three is the region where the navigation system can function. (At the beginning of each satellite's lifetime, it is maneuvered from the point it is inserted into geostationary orbit to its final station. This explains the few individual points that are far off the standard positions.) 


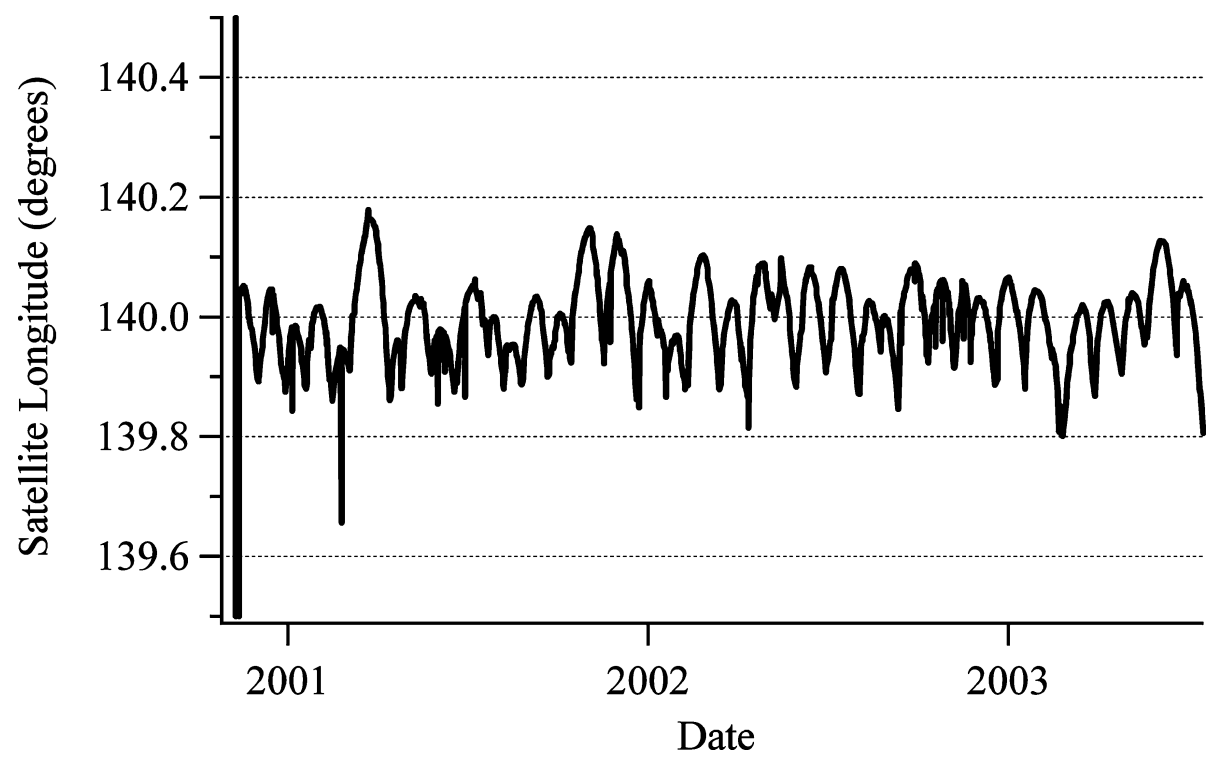

Figure 2: The details of Beidou 1A's longitudinal history. The sharp spike toward lower longitudes at approximately 2001. 2 probably corresponds to a small mismeasurement of the satellite's orbital parameters and not a physical moment of the satellite.

area on the Earth's surface where a user can employ this system. This region extends from roughly the eastern tip of the Arabian peninsular to a little east of the eastern tip of Australia. This is clearly a regional system if used for terrestrial applications.

China has maintained a fairly good record of station-keeping for all three satellites. Figure 2 shows the details of the longitudinal station-keeping for Beidou 1A. It displays the typical geostationary station-keeping profile; every 30 days or so the satellite fires a rocket engine to prevent the satellite from drifting off station-an effect caused by the small irregularities in the Earth's gravitational field. In the graph, these firings correspond to the times of rapid longitude change, in this case, at the low values of longitude or the cusps in the longitude plots. After a rocket firing, the satellite "coasts" up a local high in the gravitational potential before starting to slide back down the same slope after which the station-keeping process is repeated. China has, for the most part, kept the variations in longitude to the \pm 0.1 degrees recommended by the International Telecommunications Union. The other two Beidou satellites display similar station-keeping.

These variations correspond to absolute displacements of $150 \mathrm{~km}$ east and west as the satellite varies in longitude over the month or so between 
station-keeping. There is also a daily variation of about $\pm 40 \mathrm{~km}$ north-south because of each satellite's inclination. While these variations are relatively small compared to the orbital altitude of more than $35,000 \mathrm{~km}$, they are significant for navigational purposes. Because of these spatial variations, current orbital parameters for each satellite must be used when computing a user's position. Existing space-based navigational systems must do the same thing, only they continually broadcast the most up-to-date parameters to the users whose terminals then calculate the position estimation. As will be discussed, China's declared mode of operation does not require these parameters to broadcast since the position is calculated at the central control center. However, because the Beidou satellites are known to have transponders onboard and use them in the declared mode operation, each Beidou satellite could broadcast its orbital parameters.

\section{CHINA'S CONCEPT OF OPERATIONS ${ }^{6}$}

China, even though it has launched three satellites, says that it is using a two satellite system based on an iterative determination of a user's altitude; the third satellite being an on-orbit spare. This system is reported to work like this: each of the satellites continuously broadcast signals to all parts of the Earth that are visible to it, a user picks off a certain portion of those signals and transmits it back to the satellite. The satellite, in turn, forwards the received signal to the system's control center. Computers at the system's control center then determine the distance between the user and the satellite. This is accomplished by inferring the time-of-flight difference between satellite and user from the time the signal was originally broadcast, which must somehow be stamped with the broadcast time, ${ }^{7}$ and when the relayed user's signal reaches the control center.

The control center then combines an initial guess of the user's altitude (and hence the distance from the Earth's center), either from the last reported altitude or perhaps by using an arbitrary guess such as sea level, with the distances from the two satellites to get three distance estimates for the user's position. This determines the first estimate of the user's latitude and longitude. A map of the user's region (presumably stored digitally) is then used to make an improved estimate of the user's altitude which can then be feed back into the latitude and longitude calculation to make an improved estimate of those quantities. The next round of this iterative process could use new timing measurements or it could use the original time differences but with just an improved estimate of the altitude. It is doubtful that using additional measurements would add 
much improvement over the single iterated measurement since a significant fraction of the error is systematic, caused by such things as multiple reflections and atmospheric effects.

It has been argued ${ }^{8}$ that this mode of operation precludes military uses for the Beidou system. Those who argue this point out two facts. First, in this mode of operation, the user needs to send the satellite a signal and that would reveal the location of whatever weapon system was using the satellites for navigational purposes. Second, the system is reported to be not useable by users moving more than about ${ }^{9} 0.28 \mathrm{~km} / \mathrm{s}$ since fast moving users "might either miss or delay signals." The critical factor in understanding this seems to be the time stamp associated with the signal broadcast from the satellite.

Beidou's time stamp could be accomplished in a variety of ways even though the Beidou satellites reportedly do not have atomic clocks onboard. Since the signal's entire trip-from the satellite to the user (and to the control center), back to the satellite from the user, and finally from the satellite to the control center-can be accomplished in less than a quarter of a second (and it is the time difference that matters), each satellite could have a fairly inaccurate clock on board. Another, more straightforward way of accomplishing this would involve the control station beaming the time of an Earth-bound atomic clock to each Beidou satellite after introducing the proper delays to take into account the different path lengths to each satellite. ${ }^{10}$ Even this method, which requires six transmissions of approximately $36,000 \mathrm{~km}$ each (the distance from the ground to the geostationary satellite) when beaming the answer to the user is included, would take less than three quarters of a second travel time.

Both these methods require a user transmission for each distance measurement. Hence there would be two user transmissions-one for each satellite-for each position measurement. There would be approximately half a second delay in getting a position back, assuming that the computational time for iteratively solving for latitude and longitude as well as any electronic delays are negligible.

\section{NAVIGATION SYSTEMS USING LESS THAN FOUR SATELLITES}

In general, a user must know his position from three different reference points in order to fix his position. NAVSTAR/GPS and GLONASS enable the user to infer these three distances by first allowing him to estimate his local time; the three distances are then inferred by the difference between the time signal each satellite broadcasts and the user's local time. While this permits the user to be completely passive, at least electromagnetically, it does require him to use at 
least four satellites. (The fourth satellite can be thought of as supplying the time variable.)

There are, however, several ways that a satellite-based navigational system can function with fewer than four satellites. In fact, navigation systems can be set up using either three or two satellites, but at the cost of increasing operational complexity and corresponding reductions in utility. China has stated that its Beidou system is intended to function with just two satellites plus the constraint of a "known" altitude. ${ }^{11}$ In practice, this altitude could be determined during an iterative process where an initial guess is made about the altitude and then is corrected using a topographical map (perhaps stored digitally) as better estimates of the user's actual latitude and longitude are made. ${ }^{12}$ This process, which is treated in this article as a special case of the three satellite system, is discussed in more detail and analyzed in the section below, after the machinery for estimating position errors is introduced. However, since China has orbited a third satellite, we will first consider how such a system might function.

One method of utilizing three satellites involves the user supplying his own time standard (used for measuring the time-of-flight of the signals and hence distance to the satellites). While inconvenient, with the requirement for frequent synchronizations with the system's master clock, modern atomic clocks weighing just a few kilograms, make this workable. Another method involves having the user beam a signal up to each satellite which responds by "bouncing" the signal back after being amplified by its transponder electronics. The user then infers the distance to the satellite by measuring the time of the signal's round trip, adjusted for any delay in the satellite's transponder and in the atmosphere.

A third three-satellite method, more applicable for civilian than for military users, is to augment the satellite system with a number of ground stations. These ground stations, sometimes referred to as pseudolites ${ }^{13}$ when used in conjunction with GPS, must be within line of sight of the user. Pseudolites are used in GPS navigation to great effect when localized precision is required, such as around airports. This seriously restricts the coverage of the satellite system and, it could be argued, renders the space-based portion of the system an extremely expensive adjunct to a land system. Systems with such land-based components will not be considered in this article since their coverage, limited to areas internal to the owner's region of control, makes them unusable to any but the most defensively oriented military.

Mark Sturza ${ }^{14}$ has shown that if a user has a precision clock, he can determine his position to an accuracy determined in part by the geometry of the satellite constellation and the user's clock error. (All satellite-based navigation systems also have error contributions from ${ }^{15}$ the satellite's clock bias, the 
precision of orbit determination, errors due to noise, and errors due to multiple paths (i.e., reflections off the ground and other objects of the signal radio waves). These errors are multiplied by the factor determined by the constellation geometry. Because such a three-satellite navigation system is so unusual, Sturza's derivation of the error matrices associated with it are reproduced in an Appendix.

For this analysis, the important result from Sturza's work is represented by the user's three-dimensional position error:

$$
\sigma_{3 \mathrm{sat}}^{2}=\boldsymbol{\sigma}_{\rho}^{2}\left\{\left(\mathbf{H}_{3}^{T} \mathbf{H}_{3}\right)^{-1}+\frac{\boldsymbol{\sigma}_{b}^{2}}{\boldsymbol{\sigma}_{\rho}^{2}} \mathbf{H}_{3}^{-1} \overrightarrow{1} \overrightarrow{1}^{T} \mathbf{H}_{3}^{-T}\right\}
$$

where $\mathbf{H}_{3}$ is the matrix of cosines for the directions from each satellite to the user, $\sigma_{\rho}$ is the error associated with the electronics, etc., and $\sigma_{b}$ is the error associated with the user's local high precision clock. This article will consider the case where the user's clock is essentially errorless: $\sigma_{b}=0$. In this case, the system's error is given by

$$
\sigma_{3 \text { sat }}^{2}=\sigma_{\rho}^{2}\left(\mathbf{H}_{3}^{T} \mathbf{H}_{3}\right)^{-1}
$$

It is important to state that this error is proportional to the error derived exclusively from the geometry of the satellite constellation. The three-satellite constellation geometry that gives the smallest errors has two satellites essentially at the user's horizon and spaced $90^{\circ}$ apart while the third satellite is directly overhead, supplying the bulk of the altitude measurement. As will be seen, the Beidou constellation of three geostationary satellites, which appear almost in a line as seen from Beijing (see Figure 4), is far from optimum. Socalled "differential GPS" methods, other than the addition of any pseudolite ground station, cannot improve on this geometric factor, since we assume that the system is not trying to overcome an encryption algorithm.

This is also the error for systems, such as LocStar and GeoStar, ${ }^{16}$ that eliminate the need for the user to carry a high precision clock and, instead, simply bounce back a signal that originates with the user. In such systems, the user measures the time difference between the outgoing and returned signalsa different mode of operation from that declared for the Beidou constellation. While there is an advantage in obviating the need for the user clock that remains highly accurate for extended periods, the user of such systems must risk giving his position away by radiating the original signal. 


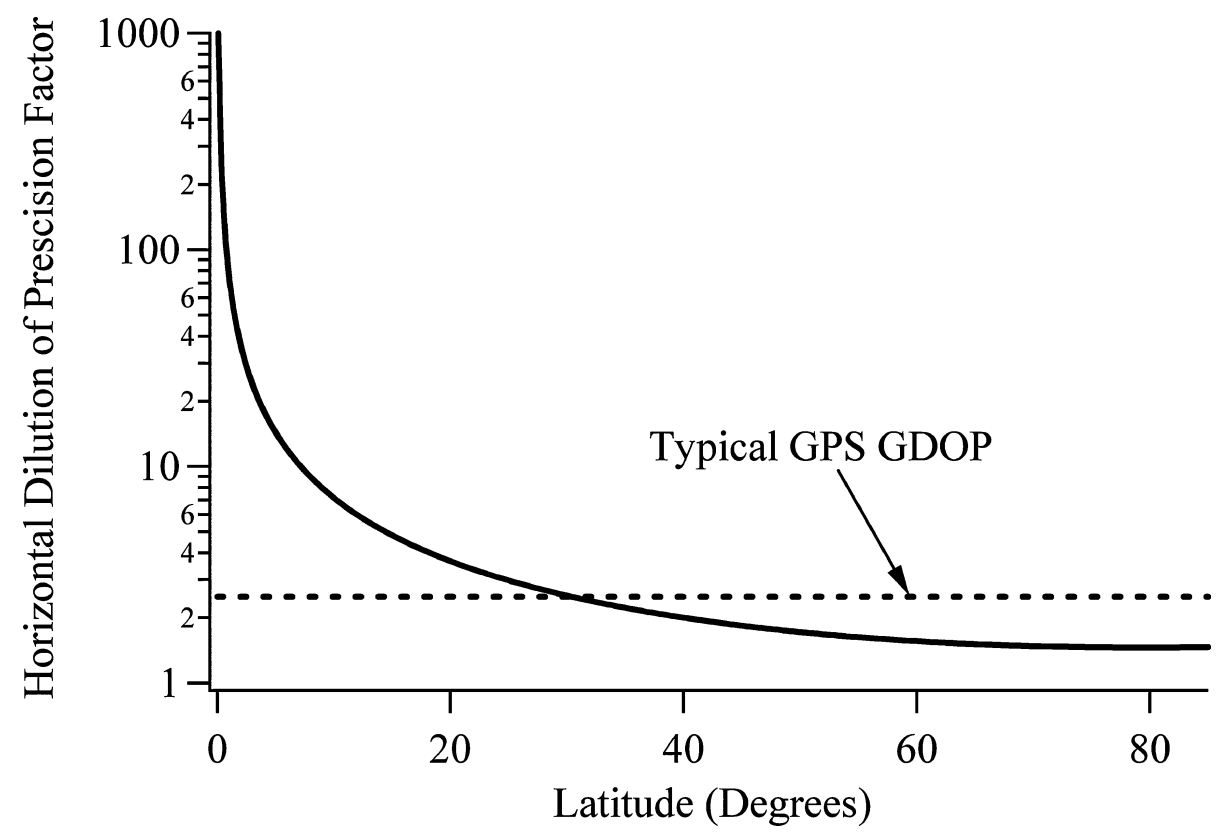

Figure 3: The Horizontal dilution of precision (HDOP) for China's two satellite system plus a known user's altitude as a constraint. Note that the error factor for the Beidou system plus altitude constraint becomes equal to and then better than a typical GPS GDOP at latitudes greater than about $30^{\circ}$. (A typical maximum GPS GDOP is shown as a dotted line.) The lowest latitude of China is approximately $20^{\circ}$, so for most internal uses, this system would give fairly accurate results. Since this system uses the altitude as a constraint, a vertical dilution of precision factor, or VDOP, is undefined.

\section{ACCURACY OF CHINA'S CONCEPT OF OPERATION}

How accurate would this position measurement be? The same formalism as was derived for the three-satellite problem can be used to estimate the final system accuracy by treating the center of the Earth as a third "satellite." Note that this third reference point obviously lies in the equatorial plane as do the Beidou satellites. The resulting horizontal dilution of precision factor is shown in Figure 3. (Since the altitude is a constraint, the vertical dilution of precision factor is undefined.) For most of China, this system would give position accuracies comparable to NAVSTAR/GPS, provided accurate altitude maps were available and there were not excessively steep slopes in the area.

While this system has reasonable accuracy for terrestrial users, when used in this sort of iterative mode, there are still some issues with understanding its final use. For instance, the number of users who can access the system is 
limited by the Beidou control center calculating each user's position and then sending it to him. In fact, the system operating in this mode seems much more like an experimental system than an operational system. If that is the case, why did China find it necessary to orbit a third satellite as an in-orbit spare? What capabilities does this third satellite give the system, and in particular, what military capabilities? Does the current system always have to be used in this iterative fashion and does the user always have to transmit a signal to the satellite, thereby giving away his position? In fact, with the launch of the third Beidou satellite, the user can remain a passive user provided he carries his own high-precision clock. This is true even if the current Beidou satellites do not have atomic clocks since the ground-based control station can broadcast time signals to each satellite for retransmission. It is interesting to note that some Chinese scientists have already published articles about this mode of operation. ${ }^{17}$

The rest of this article is devoted to studying the potential military applications of the current three-satellite system. It assumes that an accurate time signal can be broadcast from each satellite, perhaps simply as a retransmission of timing signals originating on Earth; a capability those satellites appear to already use. We also assume that each user will carry his own time reference, perhaps in the form of an atomic clock, so that all three coordinates (latitude, longitude, and altitude) can be determined simultaneously. The accuracy of this system, which is largely shaped by the geometry of the Beidou constellation, can then be used to assess the system's application for military purposes.

\section{TERRESTRIAL MILITARY USES OF THE BEIDOU NAVIGATION SYSTEM}

It is helpful to note that a four-satellite constellation can achieve a geometric dilution of precision, GDOP, value close to the theoretical optimum ${ }^{18}$ if three of the satellites are equally spaced $120^{\circ}$ apart around the user's horizon and the fourth is directly overhead. The Beidou constellation, on the other hand, has a very different geometry. Figure 4 shows the constellation as seen from a terrestrial observer in Beijing.

Using the known positions of the Beidou satellites, the horizontal and vertical dilutions of precision factors can be then be calculated according to the procedures outlined in the section above. These factors will, of course, depend on the observer's position. We choose to plot the HDOP and VDOP values as a function of latitude for a fixed longitude nearly in the center of the covered region; the same longitude as Beijing. The resulting dilutions of precision factors are shown in Figure 5. For convenience of comparison, a typical maximum 

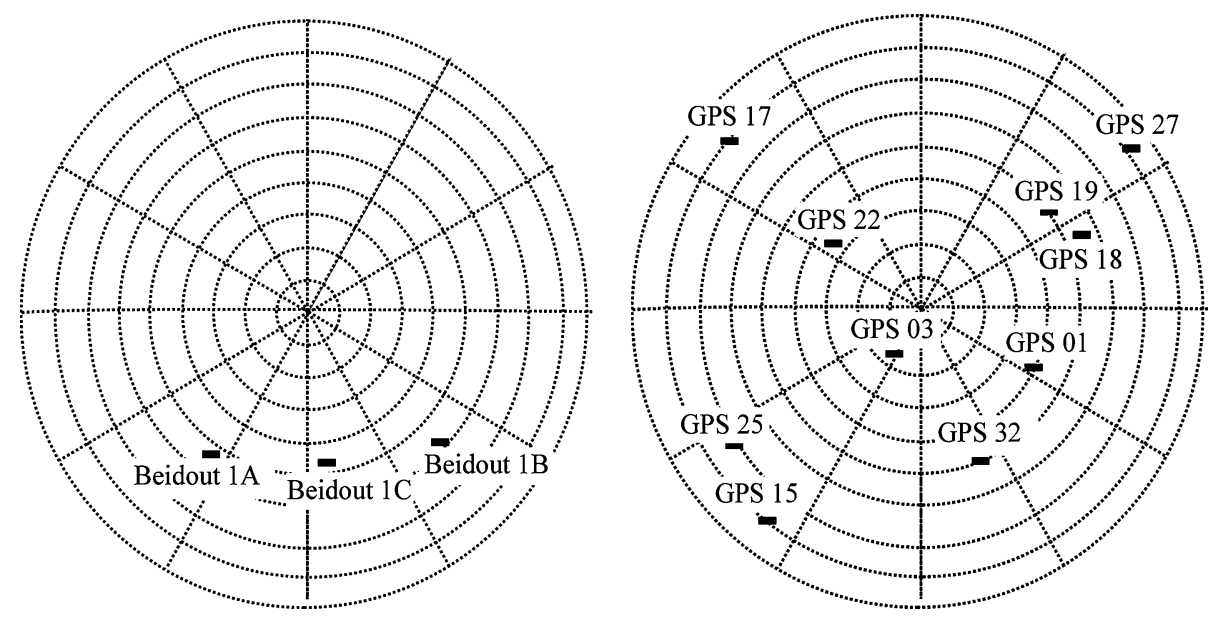

Figure 4: The Beidou constellation as seen from Beijing on the left; the actual NAVSTAR/GPS constellation as seen from Beijing (at one particular moment, since GPS satellites are not in geostationary orbit). The concentric circles represent constant elevations and the radial lines are lines of azimuth coming from the local zenith. The three Beidou satellites are shown as double triangles with their identities labeled next to them. The other dots represent stars.

acceptable GDOP ${ }^{19}$ for the NAVSTAR/GPS of 2.5 is shown. This NAVSTAR/GPS quantity, however, folds in the vertical dilution of precision factor and thus artificially improves the comparison.

As might be expected from the fact that all of the Beidou satellites are in geostationary orbits and, hence, appear to a terrestrial observer to lie nearly in a straight line, the constellation gives very large errors in determining the user's latitude, or North-South position. At the same time, it gives fairly accurate longitudinal positions.

To assess how this system could be used for military applications, it is necessary to estimate the error factor arising from all the other, nongeometric, sources of error. Without an analysis of a Beidou user's station and not knowing the errors associated with their orbital positioning, it is impossible to make an accurate, independent estimate of that error factor. However, it is possible to place an upper bound on the system's accuracy by assuming that the electronics, etc., produce an error equal to the NAVSTAR/GPS error. This of course assumes that China's electronics infrastructure is not significantly better than U.S. infrastructure, which seems to be a reasonable assumption.

It has been reported ${ }^{20}$ that NAVSTAR/GPS's military mode has an accuracy somewhat better than 10 meters. Assuming that accuracy and the reported 2.5 GDOP factor, we can estimate that all the factors contributing to the 


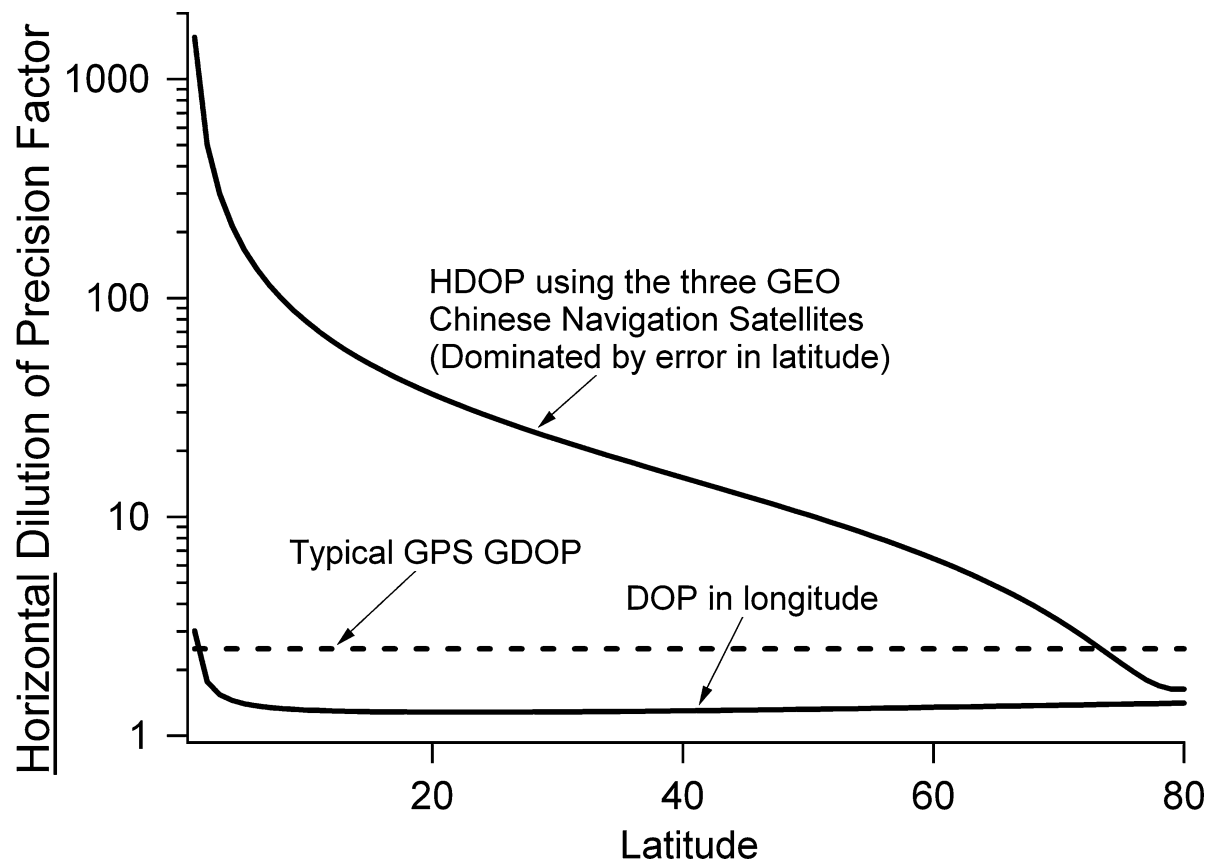

Figure 5: The horizontal dilution of precision factor, or HDOP, is shown for the Beidou satellite constellation. As can be seen from a comparison with a typical maximum GPS dilution factor of 2.5, which includes the vertical factor, the constellation's geometry results in precision considerably worse than GPS over nearly the entire area covered. The projection of the HDOP in the East-West direction is also shown.

nongeometric error produce a multiplicative scaling factor of about 3 meters. We will assume this same factor for the Chinese system as a way of placing an upper bound of the spatial error.

With that assumption, the horizontal error of the system at Taipei (with a latitude of $25^{\circ}$ North) would have a North-South error of \pm 84 meters and an East-West error of \pm 3.9 meters. This can be compared to accuracies associated with level bombing (during the Vietnam War) and modern dive-bombing (on practice ranges without air defense) of 120 meters and 10 meters respectively. (See Table 2 for a wider range of comparisons.) Of course, those bombing accuracies are the standard CEP, or circle of error probable, which corresponds to the radius at which $50 \%$ of the bombs fall within and $50 \%$ outside while the navigational system error corresponds to a more rigorous $68 \%$. However, it is likely that the positional error of the navigational system would be better than the accuracy of the bomb. By itself, the Beidou navigational system would appear 
Table 2: Comparisons of munitions accuracies.

\begin{tabular}{|c|c|}
\hline Weapon system & $\begin{array}{l}\text { Accuracy, CEP } \\
\text { (meters) }\end{array}$ \\
\hline \multicolumn{2}{|l|}{ Modern US "Smart munitions" } \\
\hline $\begin{array}{l}\text { Joint Direct Attack Munitions (JDAM), GBU 31/32 } \\
\text { with integrated inertial guidance and GPS }\end{array}$ & $<13$ \\
\hline $\begin{array}{l}\text { JDAM GBU } 31 / 32 \text { with inertial guidance only } 2 \\
\text { (for free flight times less than 100s) }\end{array}$ & $\sim 30$ \\
\hline $\begin{array}{l}\text { Conventional Air Launched Cruise Missile, } \\
\text { AGM-86D (block II) }\end{array}$ & $\sim 5$ \\
\hline \multicolumn{2}{|l|}{ Aerial bombing without inertial or GPS guidance } \\
\hline Modern dive bombing (under practice range conditions) ${ }^{4}$ & $\sim 10$ \\
\hline U.S. level bombing during World War $\|^{5}$ & 1000 \\
\hline U.S. level bombing during the Korean Warb & 300 \\
\hline U.S. level bombing during the Vietnam War ${ }^{7}$ & 120 \\
\hline \multicolumn{2}{|l|}{ Some current Chinese tactical-range missiles } \\
\hline $\begin{array}{l}\text { DF-15A (solid propellant ballistic missile with } \\
\text { inertial navigation and terminal control) }\end{array}$ & $30-45$ \\
\hline $\begin{array}{l}\text { DF-11 (solid propellant ballistic missile with } \\
\text { inertial navigation and terminal control) }\end{array}$ & 600 \\
\hline \multicolumn{2}{|l|}{ Historical missiles } \\
\hline V 1 German cruise missile 10 & 19,000 \\
\hline V 2 German ballistic missile ${ }^{11}$ & $15,000-20,000$ \\
\hline
\end{tabular}

1 Air Force Link Factsheet, http://www.af.mil/factsheet.asp?fsID=108 (14 July 2004).

2 lbid.

3 Michael Russell Rip and James M. Hasik, The Precision Revolution: GPS and the Future of Aerial Warfare, (Annapolis, MD: Navel Institute Press, 2002), p. 257.

4 T. Postol, private communication.

5 Richard P. Hallion, Precision Guided Munitions and the New Era of Warfare, Air Power Studies Centre Working Paper \#53. This paper can be found on the web at http://www.fas.org/man/dod-101/sys/smart/docs/paper53.htm (14 July 2004). The CEP information in this reference came from an Air Force briefing reference as HQ USAF/XOX, "Air Power Lethality and Precision: Then and Now," Fall 1990.

6 lbid.

7 ibid.

8 Janes Strategic Weapons System, online at www.janes.com (14 July 2004).

9 lbid.

10 Major Kirk M. Kloeppel, The Military Utility of German Rocketry During World War II, AU/ACSC/0609/91-03. (Air Command and Staff College) March 1997, p29. This paper is available online at http://research.airuniv.edu/viewabstract.aspx?id=1159 (14 July 2004).

11 Janes Strategic Weapons System, online at www.janes.com, see offensive weaponsobsolete systems, (14 July 2004).

to have insufficient accuracy to justify the expense of a space-based navigation system for military purposes.

Another possible military application for the system might involve using satellite-based navigation as an auxiliary navigation system for cruise missiles. An example would be if China's inertial navigation systems were sufficiently 
accurate to determine cross-range errors on the order of \pm 10 meters but were insufficiently accurate to determine the range to the same accuracy. (This is a hypothetical situation for which the author does not have any evidence. Instead, it is intended merely to illustrate the technical limitations of using the current Beidou constellation for terrestrial applications.) If that were the case, China could fly cruise missiles against Taipei along fixed latitude flight paths and use the Beidou system to terminate the flight. This might give China's cruise missiles accuracies comparable to U.S. cruise missiles, but only if their inertial navigational systems were equal to the cross-range task.

\section{ADJUNCTS TO THE CONSTELLATION?}

While China's current Beidou navigation system definitely cannot provide the same accuracy to guided munitions that NAVSTAR/GPS system does and most likely cannot provide much improvement over dive-bombing, there are spacebased components that could be added and still retain an indigenous, regional system that is comparable to GPS. The most straightforward of these is to add an additional four satellites in so-called Molnyia orbits. Satellites in such orbits would improve the geometry, and hence reduce the geometric error, of the system by having a satellite appear, to a user, far north of the existing geostationary satellites as well as obviating the need for the user carrying a precision clock or other schemes required for three-satellite constellations. (On the other hand, adding a fourth satellite in geostationary orbit could not produce nearly as significant an improvement in geometry as a satellite in a Molnyia orbit.) This section will consider just how much improvement would be gained by adding satellites in Molnyia orbits.

Molnyia orbits are highly elliptical and have an inclination near $63^{\circ}$. The advantage of such orbits is that a single satellite can loiter, for nearly six hours, over a point at latitudes of between $40^{\circ}$ and $60^{\circ}$. It would take four such satellites to maintain a continuous coverage in Asia. These orbits are illustrated in Figures 6 and 7, which show the orbits relative to the Earth and as seen from Bijing, respectively.

Including the additional four satellites in Molnyia orbits has a significant effect on the theoretical best performance of the Beidou system, assuming all three geostationary satellites plus at least one Molnyia satellite can be used at any given time. If that is the case, the addition of the Molnyia satellites frees the user from carrying a precise clock. It also considerably improves the constellation's geometry. (By the time one satellite in a Molnyia-type orbit moves near 


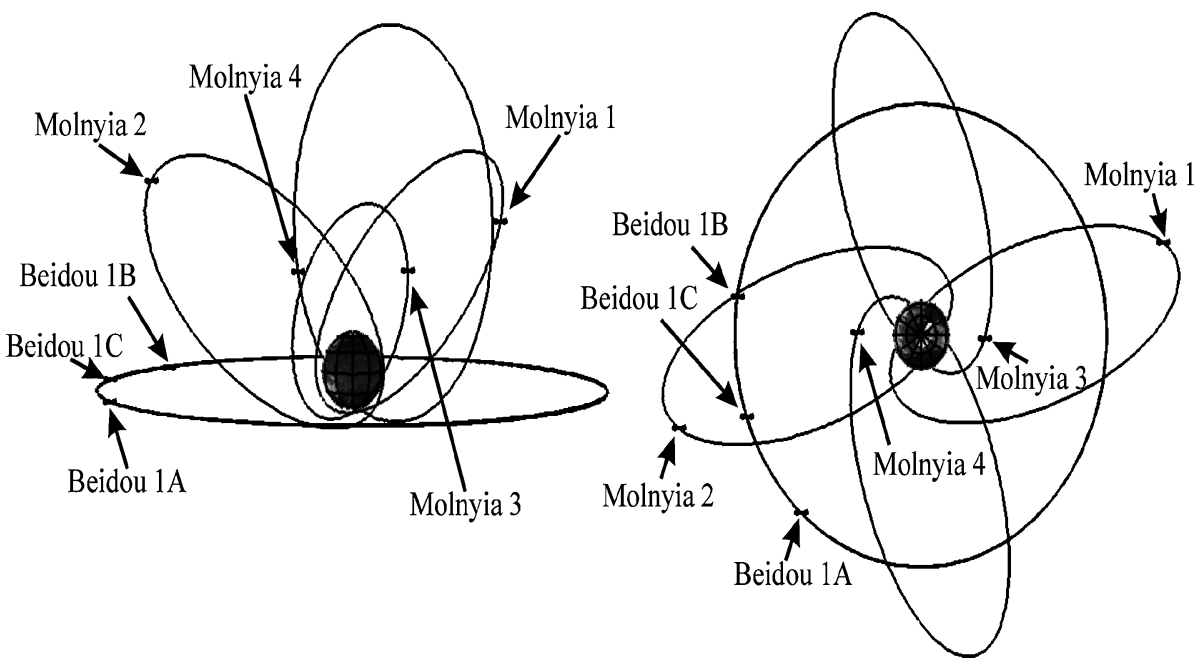

Figure 6: Orbits of the hypothetical augmented Beidou navigation system as viewed from an observer high above the equator (left) and one high above the north pole (right). The existing Beidou satellites, in geostationary orbit, are labeled as Beidou 1A, 1B, and 1C. Hypothetical adjunct satellites in Molnyia orbits are labeled "Molnyia 1" through 4.

Beidou 1B, another has appeared north of Beijing.) The resulting geometric dilution of precision factor, calculated using the standard methods for four or more satellites, ${ }^{21}$ is shown in Figure 8.

When the four Molnyia satellites are included in the constellation, the geometric dilution of precision (GDOP) and the horizontal dilution of precision (HDOP) factors are significantly reduced; primarily because of the presence of a satellite at large latitudes. In this case, we could expect the spatial accuracies to be consistently better than 30 meters. This would seem to place a Beidou/Molnyia guided munition in the same accuracy category as the JDAM with inertial guidance only (but with NAVSTAR/GPS quality guidance at the point of release).

However, China has no experience with Molnyia orbits, as illustrated by the plot of apogee vs. perigee for all of China's satellites ${ }^{22}$ in Figure 9. (All four satellites in the highly elliptical orbit region, as indicated in the figure, have inclinations less than $35^{\circ}$.) While Molnyia orbits have inclinations chosen so that their orbits should not precess, ${ }^{23}$ there is inevitably some small movement of orbital axis around the earth. This would require China to learn a new stationkeeping technique. China would also have to perfect the techniques for precision 


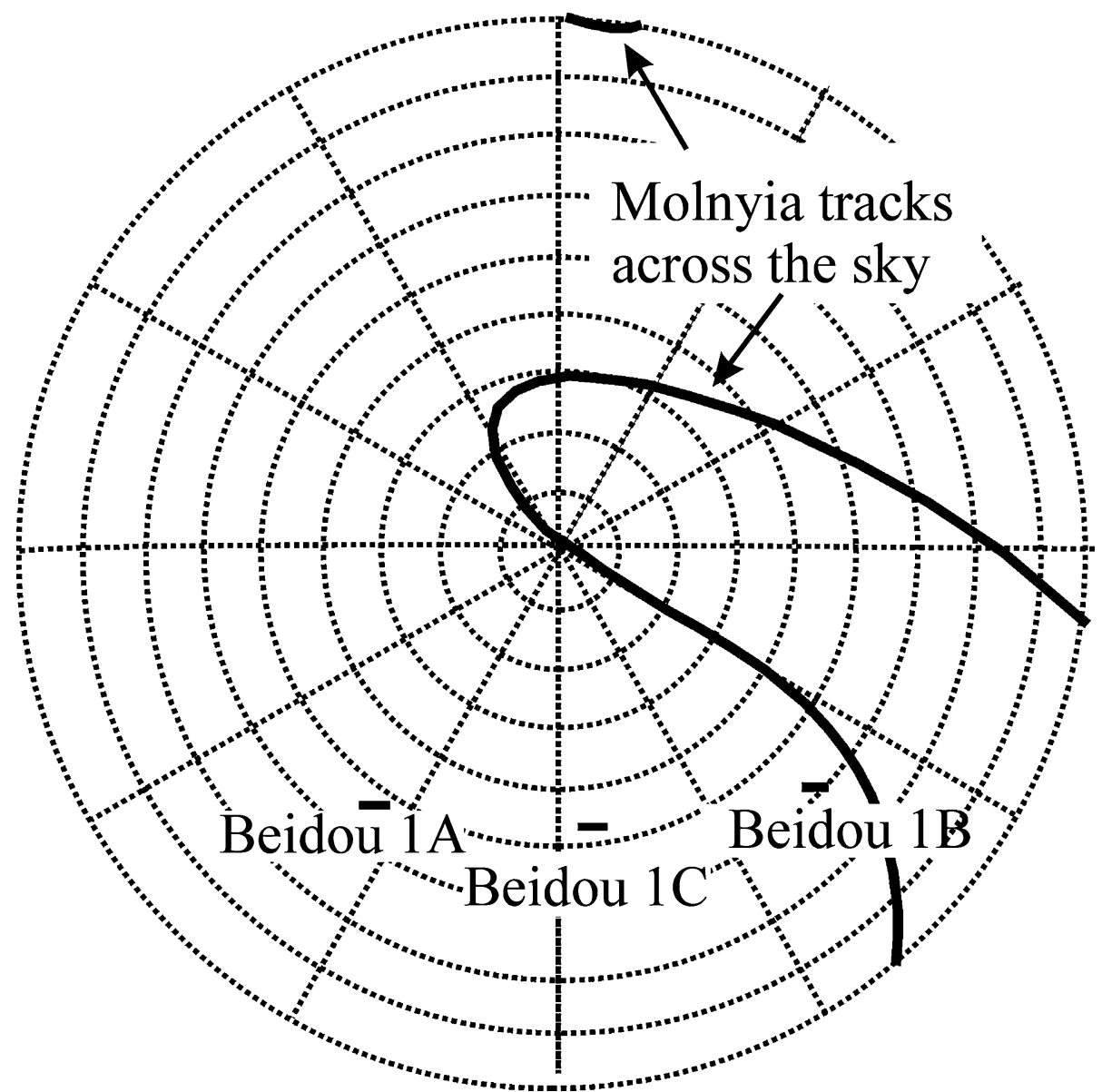

Figure 7: The track across the Beijing sky of the four hypothetical Molnyia adjunct satellites is shown as a dark line in this figure. The center of the concentric circles, from which the azimuthally radial lines are drawn, is the local zenith. The existing Beidou satellites are shown as twin triangles and labeled Beidou 1A, 1B, and 1C.

orbit determination for these unique orbits, given the fact that errors in orbital parameters directly contribute to the navigational-system users' positional errors. It is likely, given China's history of deliberately paced improvements in space and missile systems, as was illustrated by the more than two years between launching the first two Beidou satellites and the third, that it would take China many years to orbit a complete, enhanced navigation constellation if it chooses to do so. 


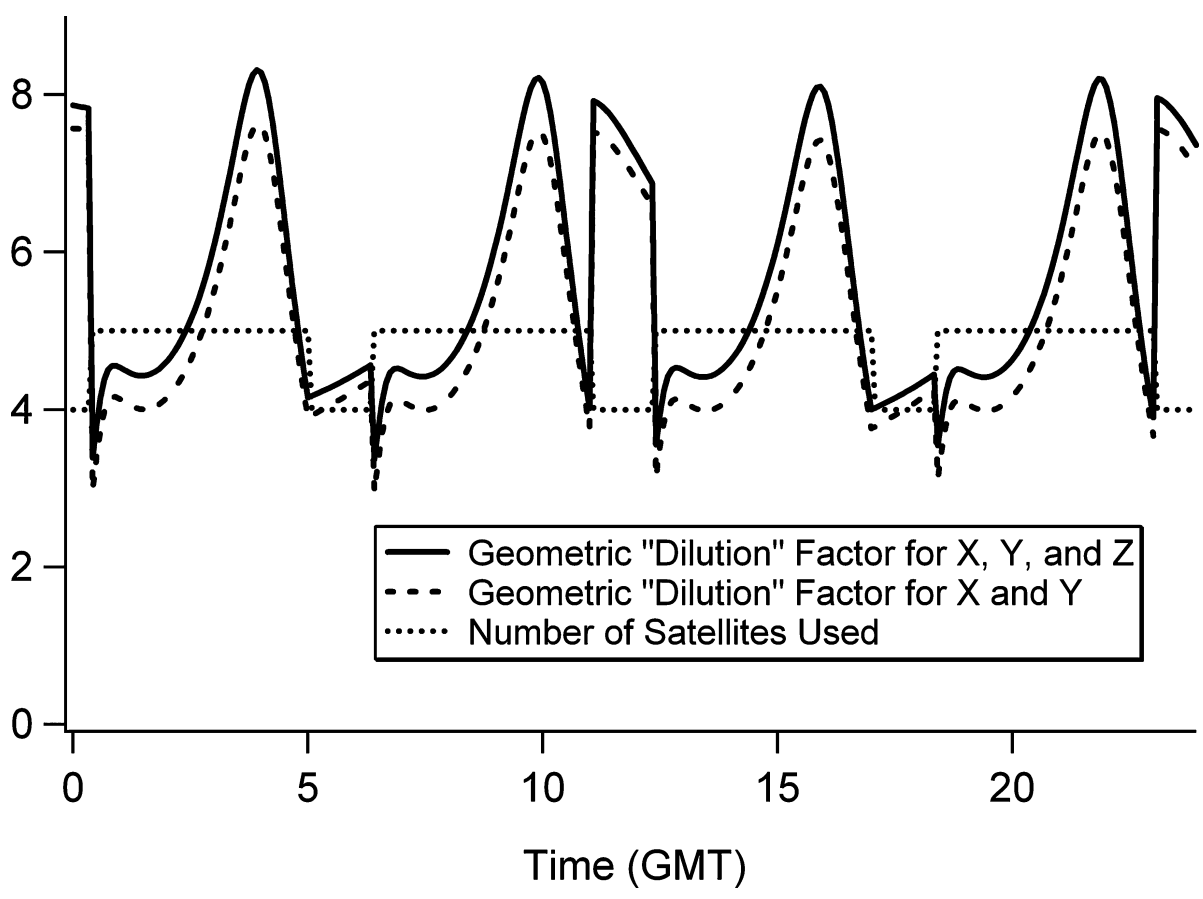

Figure 8: The various geometric dilution of precision factors are shown for the hypothetical case of the existing Beidou constellation and four additional satellites in Molnyia orbits. The four Molnyia orbits were chosen to guarantee at least one Satellite is always in position. However, during most of the time, two Molnyia satellites visible to users can be included in the position determination.

\section{STRATEGIC USE OF THE CURRENT BEIDOU NAVIGATION SYSTEM}

While the Chinese Beidou navigation system does not appear to be capable of the precision needed for terrestrial military uses, it does have a potential to assist with the navigation of China's intercontinental ballistic missiles (ICBM). We examined two possible uses of the system for aiding ICBM navigation. First, we looked at possibly using velocity information from Doppler measurements of the Beidou signals to determine more accurately ICBM thrust termination. Second, we considered using the three dimensional position determination of a post-boost vehicle provided by the Beidou system to accurately determine the Keplerian trajectory. This trajectory determination would be followed by orbital corrections. It turns out that the first possibility is impractical since the time required for accurate velocity measurements is far too long. Perhaps surprisingly, however, the second method provides China with a real possibility 


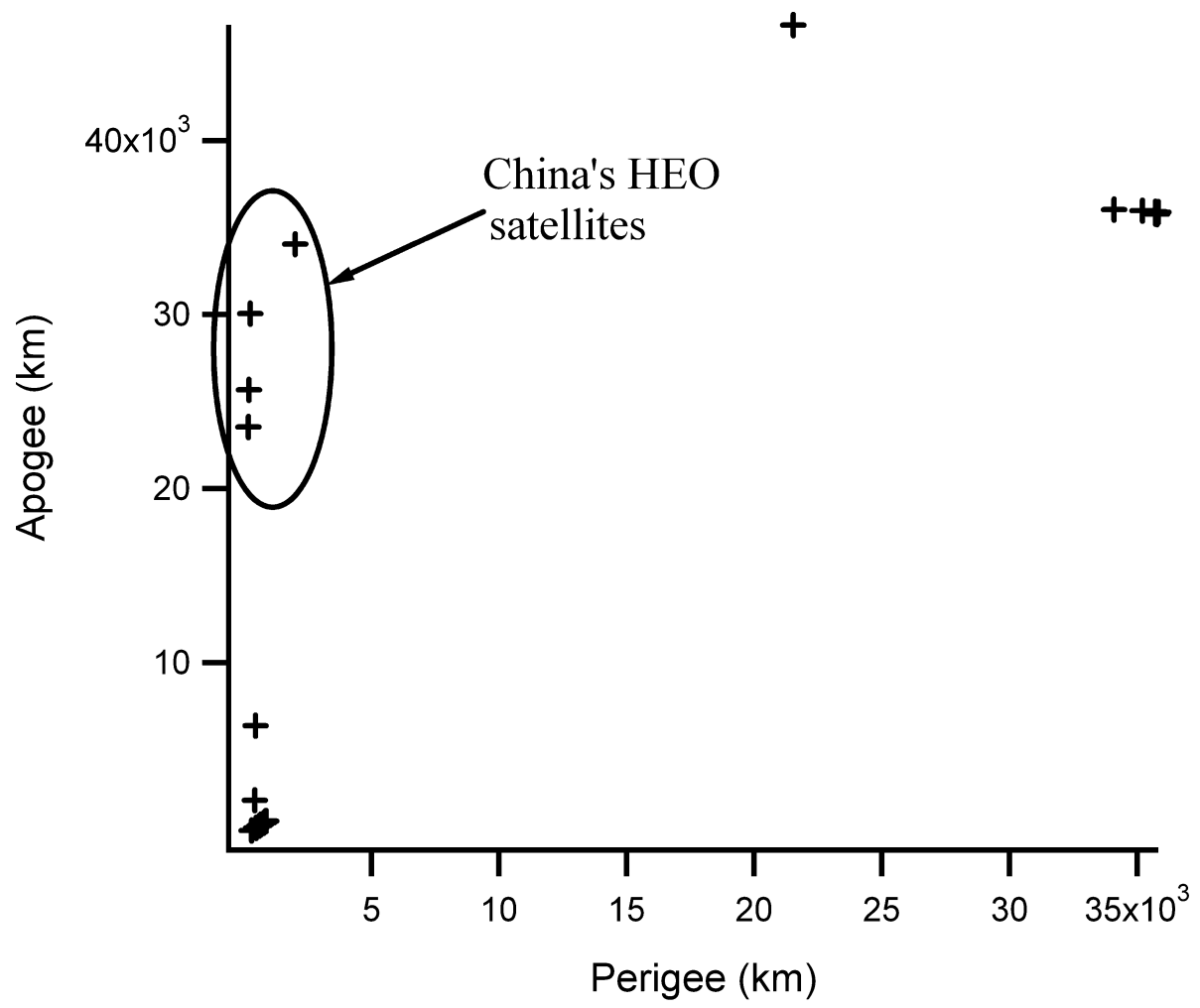

Figure 9: The apogee (altitude of the satellite at its greatest distance from the Earth) vs. the perigee (the satellite's altitude at its closest approach to the Earth) for all of China's satellites in orbit on or before 25 September 2003. The four satellites in highly elliptical orbits, $\mathrm{HEO}$, are circled. None of them has an inclination greater than $35^{\circ}$.

of improving ICBM navigation to the point where it could MIRV its ICBM warheads. Both analyses will be discussed below in the context of China's existing fleet of ICBMs.

According to published sources, China has only a small arsenal of seven DF-5A nuclear-tipped ICBMs capable of reaching the United States. ${ }^{24}$ While it is possible that these missiles have already been MIRVed, many analysts believe they carry a single, large (3-megaton) nuclear warhead. ${ }^{25}$ Estimates for the missile system's CEP range from 500 to 3,500 meters. ${ }^{26}$ Many factors contribute to the missile's impact point uncertainty including, thrust termination timing, gravitational anomalies near the launch site, and reentry uncertainties such as local weather conditions and small warhead irregularities. ${ }^{27}$ The effects present in the boost portion of the trajectory contribute the most uncertainty to 
the impact point and can, to a large extent, be characterized by the uncertainty in the vehicle's three-dimensional velocity at burnout.

To quantify these powered-flight uncertainties, a computer simulation was performed using a rotating, round Earth, which included realistic atmosphere effects. While relatively unimportant for this analysis, details of the DF-5A characteristics—such as mass ratios, engine burn times, etc.-were obtained from the civilian version ${ }^{28}$ of this missile, the Chinese space-launch vehicle, the Long March 2C. ${ }^{29}$ After adjusting the various launch parameters, such as launch azimuth, loft angle, and loft angle rate of change so that the missiles travel from their launch site at Xuanhua, China $\left(40.36^{\circ} \mathrm{N}, 115.03^{\circ} \mathrm{E}\right)^{30}$ to Washington D.C., the velocity at burnout was varied both longitudinally and in both transverse directions by small amounts. The unperturbed trajectory is shown in Figure 10. Note that the trajectory passes very close to the North Pole. Trajectories from the other DF-5A launch site, Luoning, China (at $34.23^{\circ} \mathrm{N}$ and $111.39^{\circ} \mathrm{E}$ ) also pass very close to the North Pole. This is important given the geometry of the Beidou constellation. The distribution for impact points for the various small velocity perturbations is shown in Figure 11.

Clearly, the largest changes in the impact point are caused by perturbations in the missile's velocity along its direction of flight at burnout. These are quantified in Figure 12, which shows the miss distances as a function of change in velocity for perturbations along and transverse to the nominal trajectory. Thus, a change of $1 \mathrm{~m} / \mathrm{s}$ parallel to the missile's nominal velocity (which has a magnitude of $7.2 \mathrm{~km} / \mathrm{s}$ ) produces a miss distance of $9.7 \mathrm{~km}$ while a similar transverse velocity perturbation produces a miss distance of $1.2 \mathrm{~km}$. Stated another way, the longitudinal velocity must be controlled to better than \pm 0.05 $\mathrm{m} / \mathrm{s}$ to produce a miss distance of $500 \mathrm{~m}$ or less.

If the lowest estimate for the DF-5A's CEP is correct, then China must control the missile's burnout velocity to this accuracy. Assuming an integrating accelerometer for the DF-5A, this corresponds to an accuracy of seven parts in a million. However, when thinking about using Doppler measurements from the Beidou satellites to determine engine shutoff, it is helpful to recast this in terms of a timing accuracy. After all, Doppler measurements, as will be discussed, take a certain minimum amount of time that depends solely on the desired accuracy and the carrier wave's frequency. Other than increasing the carrier frequency, electronics cannot speed up the measurement process.

In that sense, the timing requirements can be estimated from the computer model's acceleration profile, shown in Figure 13, assuming that the DF-5A does not throttle back its thrust in the last few seconds of flight. Since the DF-5A reaches peak acceleration just before shutdown, again assuming no throttling, of $70.9 \mathrm{~m} / \mathrm{s}^{2}$ this corresponds to shutting the engine down in \pm 0.0007 seconds of 


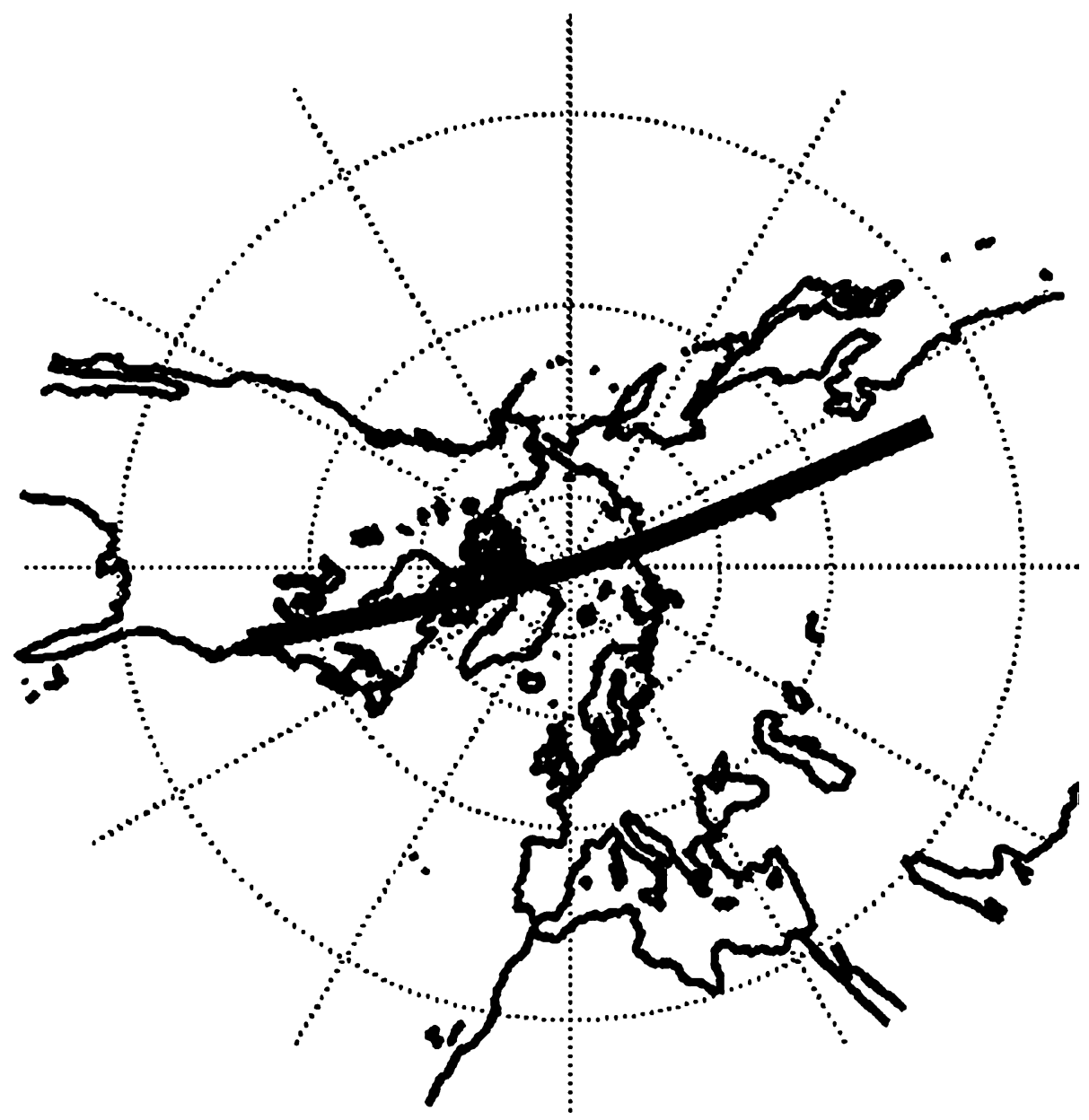

Figure 10: The unperturbed trajectory of a DF-5A from Xuanhua, China, to Washington D.C. The Eurasian land mass is on the right side of this gnomic polar projection and the North American continent is on the left. The missile's trajectory is shown as a broad line between Xuanhua and Washington D.C.

nominal burnout. Smaller miss distances would require proportionately greater timing and accelerometer precision. Of course, this timing requirement can be made somewhat less onerous by throttling down the DF-5A's liquid propellant engine. However, that method would be less workable for the solid-propellant replacement China is reportedly working on in its modernization program. ${ }^{31}$

The three satellites in the Beidou constellation are positioned to make a fairly accurate velocity measurement of a missile flying the Xuanhua (or 


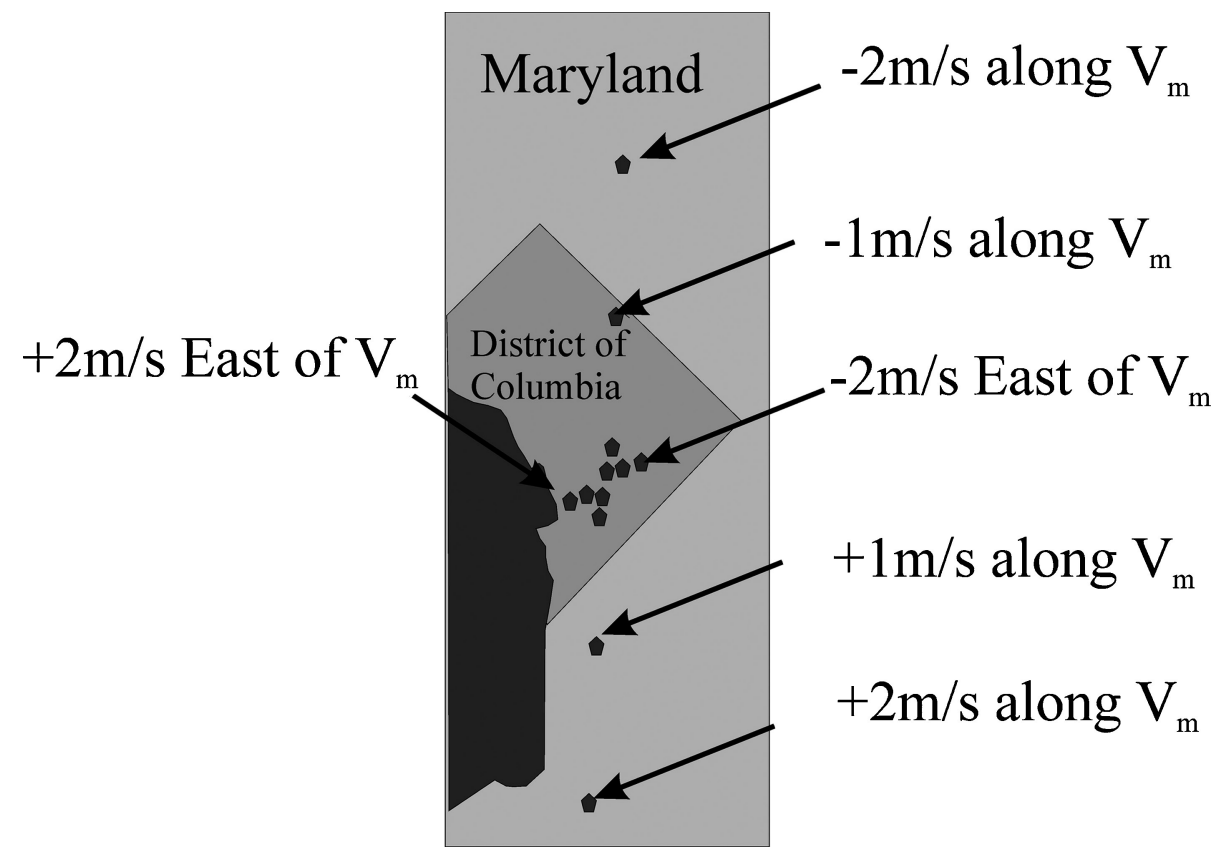

Figure 11: Impact points of DF-5A for small changes of burnout velocity. The nominal impact point is in the center of the distributions of impact points, in Southeast Washington, near the Capital.

Luoning) to Washington D.C. trajectory. Furthermore, because of the long moment arm produced by the geostationary orbit, precise knowledge of the missile's position is not required for the angular determinations that go into determining the missile vector velocity from the scalar Doppler measurements. (For instance, knowledge of the missile's position to $\pm 1 \mathrm{~km}$, which is certainly possible given what is known about China's inertial navigation technology, will produce angular errors on the order of 30 microradians.) We will therefore assume that the Doppler measurement of speed along the three lines of sight to the three satellites dominates the error. It only remains to obtain an estimate of frequency at which the Beidou satellites broadcast.

These can be estimated from reports ${ }^{32}$ that the Beidou navigation satellites are based on the same bus-the physical structure that contains the infrastructure of power, communications, attitude control, etc.-as China's DFH-3 communications satellite, which broadcasts on frequencies between four and six gigahertz. (These reports also give the DFH-3 satellite's mass at $2200 \mathrm{~kg}$, which includes the apogee insertion/station-keeping engine. This mass is consistent 


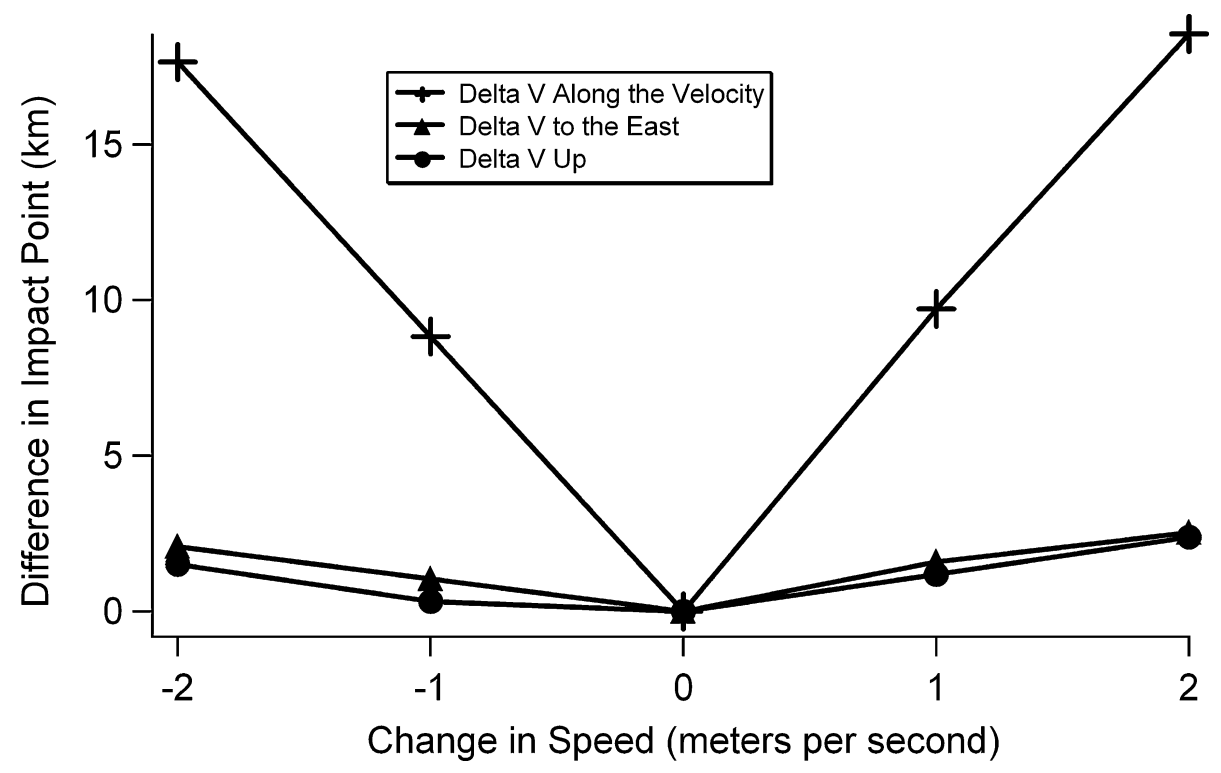

Figure 12: The distance between impact points with perturbed burnout velocities and the nominal burnout velocity for striking Washington D.C. Velocity perturbations along the missile's trajectory produce larger miss distances than perturbations transverse to the nominal velocity.

with the lift capabilities of the Long March $3 \mathrm{~A},{ }^{33}$ the Beidou launch vehicle, which can put $2,600 \mathrm{~kg}$ into geostationary transfer orbit.)

The Doppler shift is given by

$$
f_{d}=f \frac{v}{c}
$$

where $f_{d}$ is the Doppler frequency, $f$ is the frequency of the Beidou radio signal, $v$ is the velocity of ICBM with respect to the Beidou satellite and $c$ is the speed of light. The larger the broadcast frequency, the larger the Doppler shift and hence the easier it is to measure. Since the greatest broadcast frequency at which the DFH-3 bus is known to broadcast is six gigahertz, we would expect a maximum Doppler shift of $144 \mathrm{kHz}$ at the burnout speed of $7.2 \mathrm{~km} / \mathrm{s}$. Of course the actual Doppler shifts of the three Beidou signals would be somewhat less than that because none have a line-of-sight directly along the missile's burnout velocity.

Assuming the Doppler shift is used as a cutoff signal for the missile's engines, the missile's guidance and control system must differentiate between 


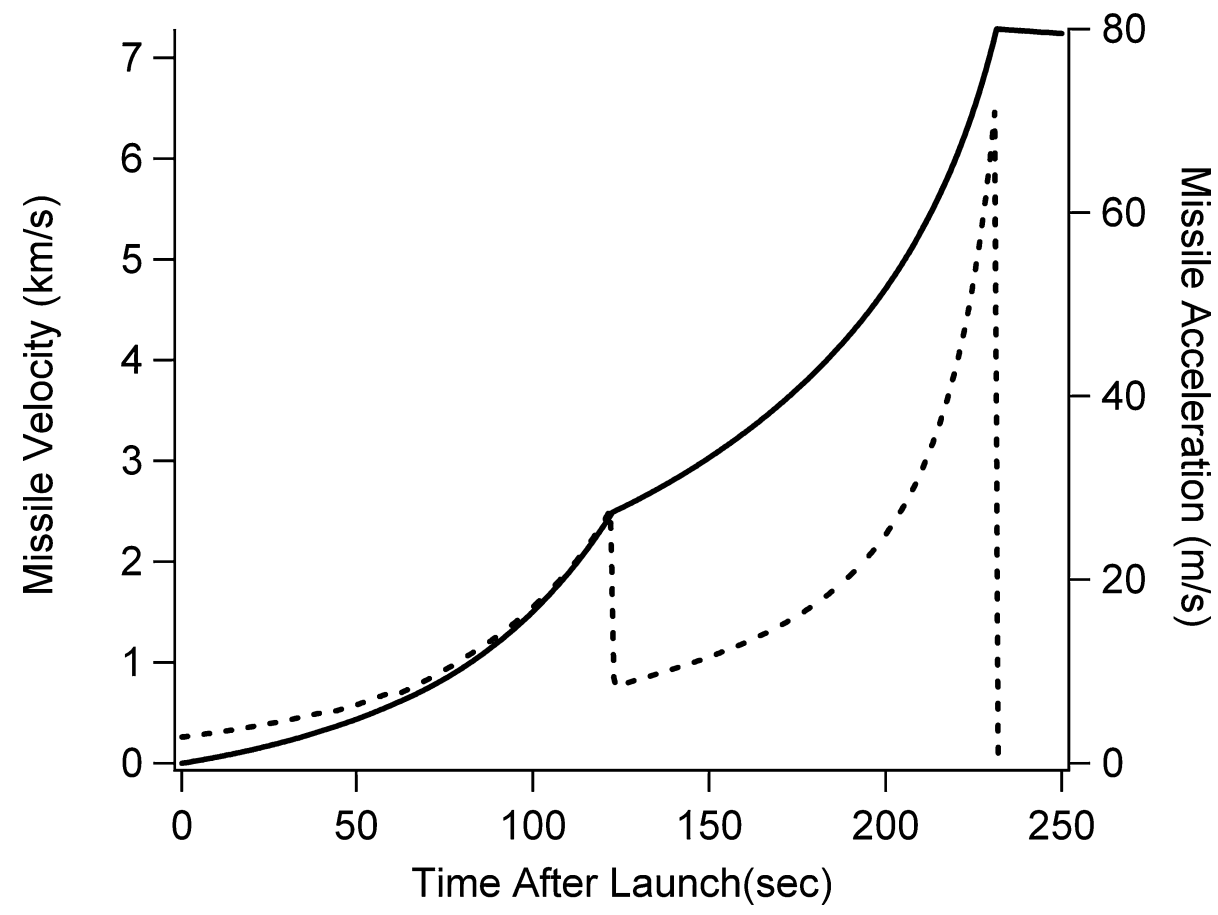

Figure 13: The acceleration (the dashed curve) and velocity (the solid curve) profiles of the DF-5A computer simulation used in this study. The sharp drop off in acceleration at roughly 125 seconds corresponds to the change in mass ratio as the first stage in dropped and the second takes over.

Doppler frequencies that correspond to velocities that differ by the desired velocity error limit. From Figure 12, it can be seen that a desired CEP of 500 meters corresponds to velocity error of $\pm 0.05 \mathrm{~m} / \mathrm{s}$. That means that the Doppler-shift measurements must be more accurate than $1.1 \mathrm{~Hz}$ out of the $144 \mathrm{kHz}$ total shift or, more importantly, out of the roughly six gigahertz carrier frequency.

While most Doppler shifts are measured by passing the signal through a bank of narrow-pass filters, ${ }^{34}$ the process can be thought of as comparing the wavelength of the incoming signal with the reference wavelength, in this case the wavelength corresponding to the desired velocity. To make a good comparison, the observer must allow a large number of wavelengths to pass by and then measure the relative phase of the two. If the incoming signal differs from the reference signal by $1.1 \mathrm{~Hz}$, the observer must wait for roughly $2.7 \times 10^{9}$ wavelengths (of the carrier beam) to pass before the relative phase differs by half a wavelength. This takes roughly half a second and sets the time scale for 
making this comparison. (Of course, it is possible that a smaller fraction of a wavelength might suffice to differentiate between the two signals. In that case, a proportionately shorter time is needed.)

On the other hand, the acceleration of the DF-5 missile, about $70 \mathrm{~m} / \mathrm{s}^{2}$, at booster burnout means that the missile changes its velocity by $35 \mathrm{~m} / \mathrm{s}$ in the half second it takes to make the measurement with the required accuracy. Even after engine shutdown, the Earth's gravitational field changes the missile's velocity by about $5 \mathrm{~m} / \mathrm{s}$ during the measurement. This is roughly 100 times greater than the required accuracy. This makes using the Beidou constellation for engine cutoff impractical. The Beidou satellite could, of course, shorten the required time for the measurement by broadcasting with a higher frequency, but it would have to be nearly 1000 gigahertz_-far higher than China has demonstrated for space-qualified transmitters-in order for the missile's velocity to change by only an amount comparable with the required accuracy during the measurement process.

Another possible method China could employ for using the Beidou constellation to improve its ICBM fleet uses a post-boost bus to correct any velocity errors that might have accumulated during powered flight. This makes use of the fact that the warhead/bus combination follows a Keplerian trajectory from burnout ${ }^{35}$ to the point where it reenters the Earth's atmosphere, and the fact that the three Beidou satellites are visible to the warhead for the first 27 minutes of its trajectory. (See Figure 14 for a view back towards the satellites

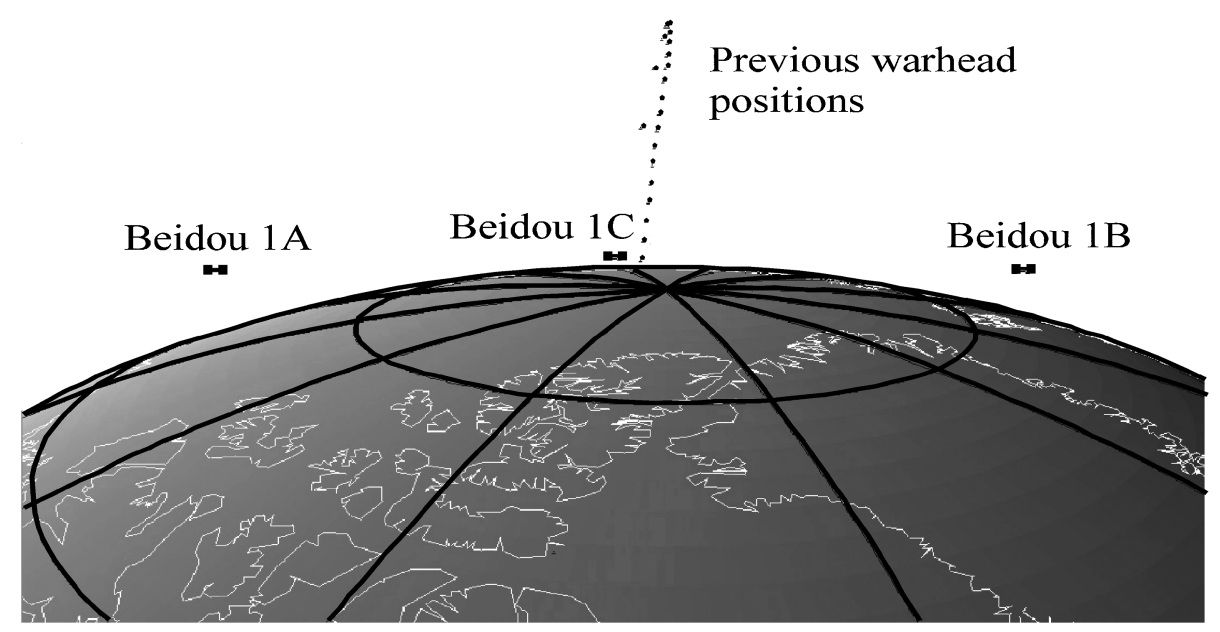

Figure 14: This figure shows the view from the warhead just before Beidou $1 \mathrm{C}$ disappears behind the Earth's limb. This is 27 minutes after its launch. The warhead is over Canada; Greenland can be seen on the right side of the globe. 
moments before they disappear behind the Earth's limb.) Keplerian trajectories, especially those traversing the large distances involved in intercontinental flight, differ dramatically for small changes in initial velocity. (This fact is at the heart of the impact point sensitivity problem being considered here.)

Making repeated, independent position measurements along the trajectory can therefore be used to determine the actual burnout velocity and therefore how much it needs to be corrected by a bus. It should be emphasized that these position measurements are not intended to measure the bus's location relative to a specific desired trajectory. Rather, they are intended to measure differences along the trajectory actually being flown and then infer the bus's velocity.

Figure 15 shows the differences in range the coasting warhead/bus combination achieves as a function of time after burnout for a number of trajectories that differ from the nominal burnout speed by small amounts. It also shows the expected positional error of the Beidou constellation projected along the warhead's velocity at each moment. It is interesting to note that the expected range error reaches a minimum at roughly the same time the range differences

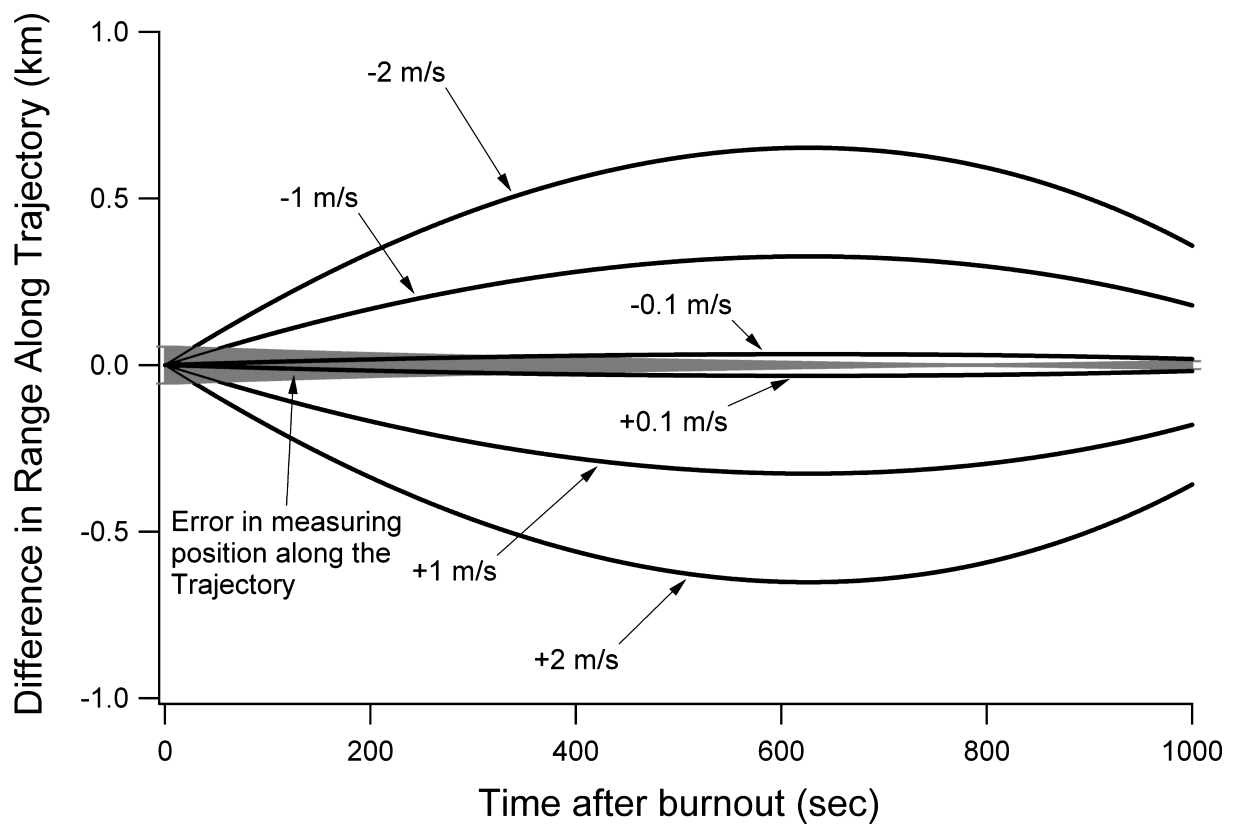

Figure 15: The differences in range for a warhead/post-boost bus from the nominal trajectory from Xuanhua to Washington D.C. as a function of time after burnout. The continuous band represents the expected error of the Beidou constellation projected in the direction of the warhead's instantaneous velocity. Note that the estimated range error reaches a minimum near the position of greatest range differences. 
are maximized, about 700 seconds after burnout. Similar plots could be made for positional differences transverse to the nominal trajectory.

Unfortunately, the factors that contribute to the error associated with a positional measurement are not independent of previous measurements. For instance, the errors associated with a satellite's orbital parameters will not vary between measurements. This means that multiple independent positional measurements cannot be made over the course of the trajectory to improve the overall absolute trajectory determination. However, the relative position of each measured point can be used to determine a trajectory with respect to a point whose absolute position is determined by the most accurate position measurement of the series. The trajectory parameters relative to this reference point, on the other hand, can be improved by making a large number of positional measurements. This is sufficient for determining the velocity corrections to a much higher precision than any single measurement would allow. Nevertheless, if China were willing to wait 500 hundred seconds after burnout (or about 12 minutes after launch in the 35 minute trajectory) it would take only a few positional measurements to discriminate between trajectories with sufficient accuracy to produce the 500 meter CEP because the GDOP continues to improve.

How would this information be used? Once an accurate estimate of the burnout velocity has been made, the coasting bus could reset its gyroscopes and accelerometers to the position and velocity determined by the Beidou system. This would essentially erase any errors that had accumulated during the powered flight portion of the trajectory. Then the bus would either maneuver to correct the small velocity differences-only a few meters per second change would be needed - to re-aim the warhead for its intended target. Or the bus could maneuver several times, relying solely on its reset internal guidance system, and drop off several warheads to different targets long its flight path-a change in targeting facilitated by the close proximity of the Eastern seaboard population centers. It should be noted that China could test this system by using it to determine the orbital parameters of its satellites in near polar orbit.

Thus, while it may seem counterintuitive, China's Beidou constellation of navigation satellites provides sufficient accuracy for guiding nuclear-tipped intercontinental ballistic missiles but is not accurate enough for conventional tactical weapons.

\section{CHINA'S NUCLEAR DOCTRINE AND THE BEIDOU SATELLITES}

This article has tried to determine the military capabilities of China's Beidou constellation of satellites. However, theoretical capabilities do not 
automatically imply actual motivations. It is possible that China has launched this system of satellites as part of a civilian research and development program and does not really care that its terrestrial applications are so restricted.

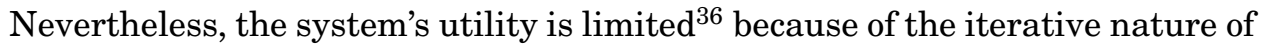
its two-satellite mode of operation or its accuracy is limited for terrestrial uses in the three-satellite mode. Because of this and the fact that the system, like any space-based system, is very expensive, we are naturally led to speculating about those applications for which it does seem to be well suited, in this case its strategic uses.

Many analysts have concluded that China has long had a nuclear doctrine based around a delayed second strike. ${ }^{37}$ This policy relied on having a few survivable missiles carrying large-yield nuclear warheads aimed at population centers. As such, China did not need excessive accuracy for its warheads. For instance, the reported 3-megaton warhead currently on the DF-5A would produce a 2 psi overpressure-enough to shatter ${ }^{38}$ concrete or cinderblock walls as well as produce large numbers of fatalities-at a radius of 19 $\mathrm{km},{ }^{39}$ far greater than even the largest CEP estimates of 3,500 meters for the DF-5A.

Even if China modernizes its nuclear forces, as some Western analysts expect, to include MIRVed warheads and consequently has to reduce their yield to save weight, it is doubtful that China would need to improve its missile accuracy. For instance, if China replaced its large, multimegaton warhead with warheads in the 150 to 350 kiloton $^{40}$ range, the equivalent blast range would only shrink to $7 \mathrm{~km}$. This is still twice the largest CEP estimate for the existing missiles. Therefore, it seems doubtful that China would need this expensive space-based navigation system for its nuclear modernization program if it were going to retain its current counter-value system of deterrence unless it was responding to some other change in the strategic environment.

It is even more unlikely that China is switching to a counter-force strategy or a command and control decapitation strike. The United States' nuclear forces are essentially sized to survive a nuclear first strike from the former Soviet Union, which had many more nuclear weapons than China can hope to produce in the foreseeable future. A much more likely explanation is that China would use a MIRVed system to threaten additional U.S. cities. A limited space-based navigation system with the accuracies currently deliverable from the Beidou constellation could contribute significantly to such a modernization program. Furthermore, the system could be viewed as a response to the proposed U.S. ground-based missile defense system since it is geared to maneuvering the bus near the mid-point of the trajectory, after a U.S. interceptor has been launched. 
Appendix

\section{DERIVATION OF GEOMETRIC ERRORS ASSOCIATED WITH A THREE SATELLITE CONSTELLATION OF NAVIGATION SATELLITES}

Sturza $^{41}$ starts with the definition of pseudorange (given by the time difference between the user's local time and local time broadcast by the satellite as received by the user) residuals, $\rho$, between each satellite and the user:

$$
\vec{\rho}=\mathbf{H}_{3} \vec{x}+b \overrightarrow{1},
$$

where $\mathbf{H}_{3}$ is a matrix containing the direction cosines from the user to each satellite. Here

$$
\vec{x}=\left[\begin{array}{c}
\Delta x \\
\Delta y \\
\Delta z
\end{array}\right]
$$

is the difference between the user and a hypothetical point whose position is assumed known,

$$
\vec{\rho}=\left[\begin{array}{c}
\Delta \rho_{1} \\
\Delta \rho_{21} \\
\Delta \rho_{3}
\end{array}\right]
$$

is the pseudorange residual vector,

$$
\mathbf{H}_{3}=\left[\begin{array}{lll}
\alpha_{1 x} & \alpha_{1 y} & \alpha_{1 z} \\
\alpha_{2 x} & \alpha_{2 y} & \alpha_{2 z} \\
\alpha_{3 x} & \alpha_{3 y} & \alpha_{3 z}
\end{array}\right]
$$

is the array of the direction cosines (see Appendix Figure 1),

$$
\overrightarrow{1}=\left[\begin{array}{l}
1 \\
1 \\
1
\end{array}\right]
$$

and $b$ is the user's clock bias.

The correction to the position of the user is then given by $\vec{x}=\mathbf{H}_{3}^{-1}[\vec{\rho}-b \overrightarrow{1}]$.

More importantly for this analysis, the position correction error covariance is given by

$$
\operatorname{cov}(\vec{x})=\mathbf{H}_{3}^{-1}\left[\sigma_{\rho}^{2} I+\sigma_{b}^{2} \overrightarrow{1} \overrightarrow{1}^{T}\right] \mathbf{H}_{3}^{-T}=\sigma_{\rho}^{2}\left\{\left(\mathbf{H}_{3}^{T} \mathbf{H}_{3}\right)^{-1}+\frac{\sigma_{b}^{2}}{\sigma_{\rho}^{2}} \mathbf{H}_{3}^{-1} \overrightarrow{1} \overrightarrow{1}^{T} \mathbf{H}_{3}^{-T}\right\},
$$

where $\sigma_{b}^{2}$ is the user's clock bias error variance. 


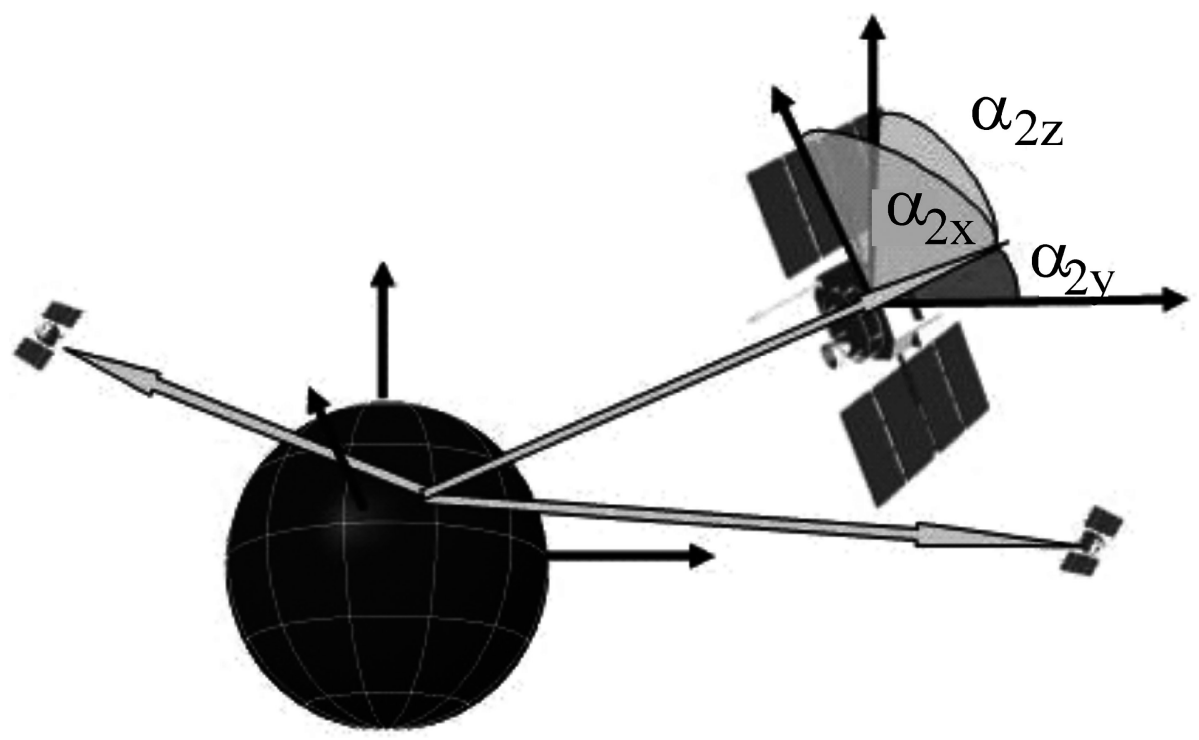

Appendix Figure 1: The vectors from the user to each of the three satellites in the Beidou constellation are shown as are two of the three direction cosine angles for the (arbitrarily numbered) satellite number 2 . The standard coordinate system, with the X-axis going to the prime meridian and the Z-axis along the north pole, is used. Note that the direction of the direction cosines is from the user to the satellite.

For the rest of this article, we will assume that the user's clock bias error variance is negligible compared to the error associated with the pseudorange, i.e., $\sigma_{b}^{2} \ll \sigma_{\rho}^{2}$. With this simplifying assumption, the position error covariance associated with the three satellite system and a user with a precise clock is given by $\sigma_{\rho}^{2}\left(\mathbf{H}_{3}^{T} \mathbf{H}_{3}\right)^{-1}$.

Thus, the error is comprised of the product of two terms; one is determined simply by the geometry of the constellation-as viewed by the user-and the other is a combination of all the other factors associated with all space-based navigation systems as mentioned above. It is helpful to consider the geometric factor alone, often referred to as the "geometric dilution of precision" factor, and to break it down into a total geometric factor, given by

$$
\operatorname{GDOP}_{3}=\sqrt{\operatorname{Trace}\left(\mathbf{H}_{3}^{T} \mathbf{H}_{3}\right)^{-1}}=\sqrt{V_{x}+V_{y}+V_{z}} .
$$

Horizontal and vertical dilution of precision factors are given by transforming the direction cosine matrix into the user's local coordinate system with the $\mathrm{X}$ and Y coordinates lying in the plane tangent to the Earth's surface at that point 
and the $\mathrm{Z}$ axis pointing out radialy. Thus

$$
\mathrm{HDOP}_{3}=\sqrt{V_{x}+V_{y}}
$$

and

$$
\mathrm{VDOP}_{3}=\sqrt{V_{z}}
$$

for the horizontal and vertical dilution of precision factors, respectively.

\section{NOTES AND REFERENCES}

1. J. J. Spilker Jr. and Bradford W. Parkinson, Overview of GPS Operation and Design, in Bradford W., Parkinson and James J. Spilker Jr. (eds.), Global Position System: Theory and Applications, Volume 1 (Washington D.C.: American Institute of Aeronautics and Astronautics, Inc., 1996).

2. As of 2 January 2004, this website was http://www.cast.ac.cn/en/printpage.asp? ArticleID $=36$

3. Ibid.

4. Some analysts claim that this mode could be used by the Chinese military in locating the launch points for their next generation of mobile ICBMs. (David Wright, private communication.) The mobile launchers could, of course, just go to presurveyed launch points.

5. The information in Table 1 and in fact all calculations in this article based on orbital positions, are derived from information provided by NASA's Orbital Information Group webpage (http://oig1.gsfc.nasa.gov/) and based on an ephemeris of 31 December 2003.

6. I would like to thank Prof. Li Bin, Director, Arms Control Program, Tsinghua University, Beijing, for summarizing for me the conception of operations for the Beidou system as presented in Gao Lu, "Double-Star Navigation System," Contemporary Communication (Xiandai Tongxun) (in Chinese), No. 10, 1997, p. 20. "Beidou-1, Navigating for China," Information of Remote Sensing (Yaogan Xinxi) (in Chinese), No. 2, 2003, p. 50. Wei Wucai, "Comparing Beidou Navigation System and GPS," Marines Navigation Technology (Hanghai Jishu) (in Chinese), No. 6, 2003, pp. 15-16.

7. This time stamp is needed to avoid the equivalent of a radar system's "range ambiguity" problem. It could be as simple as separating square wave pulses by more than the round trip travel time from the satellite to the user, approximately a quarter of a second, or it could be as complex as encoding a sequence number into a train of square waves. It should be noted that since the satellite is acting as a transponder for ground signals, this time stamp algorithm could be changed at any time without making any hardware changes on the satellite.

8. Li Bin, Director, Arms Control Program, Tsinghua University, Beijing, private communication.

9. Wang Xiaojin and Wang Xia, "Understanding "Beidou One" Navigation System," Marines Navigation Technology (Hanghai Jishu) (in Chinese) No. 1, 2004, p. 31., No. 6, 
2003. Again, the author would like to thank Li Bin, Director of the Arms Control Program at Tsinghua University, Beijing, for summarizing this paper.

10. Li Bin has stated that the signal goes back and forth "between the ground and the satellite four or five times," which seems to indicate that this is the actual method of operation.

11. Li Bin, private communication.

12. Ibid.

13. Bryant D. Elrod and A. J. Van Dierendonck, Pseudolites, in Bradford W. Parkinson and James J. Spilker Jr. (eds.), Global Position System: Theory and Applications, Volume 2, (Washington D.C.: American Institute of Aeronautics and Astronautics, Inc., 1996), pp. 51-79.

14. Mark A. Sturza, "GPS Navigation Using Three Satellites and a Precise Clock," Navigation: Journal of the Institute of Navigation, vol. 30, (1983), pp. 146-156.

15. J. J. Spilker Jr., Satellite Constellation and Geometric Dilution of Precision, in Bradford W. Parkinson and James J. Spilker Jr. (eds.), Global Position System: Theory and Applications, Volume 1, (Washington D.C.: American Institute of Aeronautics and Astronautics, Inc., 1996), pp. 177-208.

16. I would like to thank Gregory Kulacki of the Union of Concerned Scientists for pointing this system out to me.

17. Lin Xueyuan and Liu Jianye, "The Study on Improvement of "Beidou" Double-Star Navigation System and Its Algorithm," Chinese Journal of Space Science (Kongjian Kexue Xuebao) (in Chinese), Vol. 23, No. 2 (2003), pp. 149-154. Again, the author would like to thank Li Bin, Director of the Arms Control Program at Tsinghua University, Beijing, for summarizing this paper.

18. J. J. Spilker Jr., Satellite Constellation and Geometric Dilution of Precision, in Bradford W. Parkinson and James J. Spilker Jr. (eds.). Global Position System: Theory and Applications, Volume 1, (Washington D.C.: American Institute of Aeronautics and Astronautics, Inc. 1996), pp. 197-198.

19. J. J. Spilker Jr. and Bradford W. Parkinson, Overview of GPS Operation and Design, in Bradford W. Parkinson and James J. Spilker Jr. (eds.), Global Position System: Theory and Applications, Volume 1, (Washington D.C.: American Institute of Aeronautics and Astronautics, Inc., 1996), p. 36.

20. Ibid.

21. See for example Reference 6 .

22. From information provided by NASA's Orbital Information Group webpage (http://oig1.gsfc.nasa.gov/, 14 July 2004) which provides historical orbital elements to all most satellites that have ever been launched, including all of China's.

23. James R. Wertz, Mission Geometry; Orbit and Constellation Design and Management (El Segundo, CA: Microcosm Press, 2001), pp. 85-85.

24. William M. Arkin, Robert S. Norris and Joshua Handler, Taking Stock: Worldwide Nuclear Deployments 1998 (Washington D.C.: Natural Resources Defense Council, Inc.), p. 89 .

25. Jane's Strategic Weapons System, online at www.janes.com (14 July 2004). 
26. This range of DF-5A CEPs is from the FAS website at http://www.fas.org/nuke/ guide/china/icbm/df-5.htm. (14 July 2004), Jane's online, on the other hand, lists the CEP as 800 meters.

27. Mathew Bunn, "Technology of Ballistic Missile Reentry Vehicles," Report no. 11 of the Program in Science and Technology for International Security, MIT, March 1984, p. 12.

28. Jane's Strategic Weapons System, online at www.janes.com for the DF-5 (14 July 2004).

29. China Academy of Launch Vehicle Technology, LM-3A User's Manual, which is available on the web at http://www.calt.com.cn/new/english/\# (14 July 2004).

30. William M. Arkin, Robert S. Norris, Joshua Handler, Taking Stock: Worldwide Nuclear Deployments 1998 (Washington D.C.: Natural Resources Defense Council, Inc.) p. 89

31. Jane's online service at www.janes.com (14 July 2004) reports that the three-stage solid-propellant DF-41 is intended to replace the DF-5A around 2005.

32. Mark Wade, Encyclopedia Astronautica at http://www.astronautix.com/craft/beidou. htm

33. China Academy of Launch Vehicle Technology, LM-3A User's Manual, Chapter 1, page 1 , which is available on the web at http://www.calt.com.cn/new/english/\# (14 July 2004).

34. George W. Stimson, Introduction to Airborne Radar, 1st Edition (El Segundo, CA: Hughes Aircraft Company), pp. 359-360.

35. The computer model for the DF-5 used here shows that the missile burns out at approximately $160 \mathrm{~km}$ altitude, well outside Earth's effective atmosphere.

36. Some analysts argue that the declared mode of operation is not really limited since the central control center is assumed to have a detailed, high precision, digital altitude map of the entire area of coverage (David Wright, private communication). However, obtaining such a map, while certainly possible, is expensive and China has declared only that the system is used for "road traffic, rail transport, [and] offshore operation[s]," hinting that they do not have such a map for the entire area of coverage. Instead, they seem to have only such maps for their road system or railroad tracks. Offshore operation of course can accurately assume sea level in their altitude constraints. It is in this sense that the declared mode of operation seems limited.

37. The Nuclear Threat Initiative gives a concise review of China's nuclear doctrine on their website, including links to a number of Chinese official documents. This can be reached at http://www.nti.org/db/china/doctrine.htm (14 July 2004).

38. Samuel Glasstone, ed., The Effects of Nuclear Weapons, The United States Atomic Energy Commission, Revised Edition, February 1964, p. 163.

39. This and other nuclear effects were calculated using the Nuclear Bomb Effects Computer included with Glasstone's The Effects of Nuclear Weapons.

40. China tested several nuclear designs in this range between 1966 and 1983, according to Jane's Online, www.janes.com, see CSS-4 (DF-5), (14 July 2004).

41. Mark A. Sturza, "GPS Navigation Using Three Satellites and a Precise Clock," Navigation: Journal of the Institute of Navigation, vol. 30 (1983), pp. 146-156. 